University of Louisville

ThinkIR: The University of Louisville's Institutional Repository

Electronic Theses and Dissertations

8-2016

\title{
Mechanisms responsible for the development of causal perception in infancy.
}

Nicholas A. Holt

University of Louisville

Follow this and additional works at: https://ir.library.louisville.edu/etd

Part of the Child Psychology Commons, Cognition and Perception Commons, Cognitive Psychology Commons, and the Developmental Psychology Commons

\section{Recommended Citation}

Holt, Nicholas A., "Mechanisms responsible for the development of causal perception in infancy." (2016). Electronic Theses and Dissertations. Paper 2498.

https://doi.org/10.18297/etd/2498

This Doctoral Dissertation is brought to you for free and open access by ThinkIR: The University of Louisville's Institutional Repository. It has been accepted for inclusion in Electronic Theses and Dissertations by an authorized administrator of ThinkIR: The University of Louisville's Institutional Repository. This title appears here courtesy of the author, who has retained all other copyrights. For more information, please contact thinkir@louisville.edu. 


\title{
MECHANISMS RESPONSIBLE FOR THE DEVELOPMENT OF CAUSAL PERCEPTION IN INFANCY
}

\author{
By \\ Nicholas A. Holt \\ B.S., Morehead State University, 2011 \\ M.S., University of Louisville, 2013

\begin{abstract}
A Dissertation
Submitted to the Faculty of the

College of Arts and Sciences of the University of Louisville

in Partial Fulfillment of the Requirements

for the Degree of
\end{abstract} \\ Doctor of Philosophy \\ in Experimental Psychology \\ Department of Psychological and Brain Sciences \\ University of Louisville \\ Louisville, Kentucky
}

August 2016 

MECHANISMS RESPONSIBLE FOR THE

\title{
DEVELOPMENT OF CAUSAL PERCEPTION IN INFANCY
}

\author{
By
}

Nicholas A. Holt

B.S., Morehead State University, 2011

M.S., University of Louisville, 2013

A Dissertation Approved on

July 22, 2016

by the following Dissertation Committee

Cara H. Cashon, $\mathrm{PhD}$

Dissertation Director

Carolyn B. Mervis, PhD

Guy O. Dove, PhD

Marci S. DeCaro, PhD

Nicholaus S. Noles, PhD 


\section{DEDICATION}

This dissertation is dedicated to my grandmother, Mae Summers.

Thank you for always believing in me. 


\section{ACKNOWLEDGEMENTS}

First, I would like to express my sincerest gratitude and appreciation to Cara Cashon, whose unwavering guidance over the past five years has made this project possible. Thank you for providing me with the freedom and encouragement to pursue my research interests, even though sometimes my ideas may be far-fetched. I will never forget how much fun I had working on papers with you for long hours in very cold coffee shops. You have made me a measurably better writer and scientist. Your constant enthusiasm and passion for both your students and your work has truly been an inspiration to me. I could not have asked for a better mentor.

I would also like to recognize Carolyn Mervis and Guy Dove, who have provided insightful suggestions and encouragement since the early days of my interest in the topic of causal perception during my preliminary exam. Your expertise has been instrumental to the development of my ideas. I am especially grateful to Carolyn Mervis for providing her support throughout my graduate studies, and also for making incredible lemon bars. I would also like to express my sincerest thanks to Marci DeCaro and Nick Noles for contributing their time and constructive comments throughout the dissertation process.

I could not have made it through graduate school without a wonderful group of labmates. Ohryeong Ha and Chris DeNicola deserve special thanks for teaching me a great deal about conducting infant research. Thank you to Lauren Helton for playing devil's advocate during the early stages of this project. I am also particularly grateful to 
Kate Dixon and Nonah Olesen for providing a constant source of laughter and encouragement, which has made my last year in the Infant Cognition Lab one that I will truly miss. I also want to thank all of the members of the Infant Cognition Lab who have helped with data collection and coding on this project, but specifically Payal Pal for her tireless work coding hours upon hours of infant play session videos. Additionally, I am greatly indebted to all the families who kindly volunteered their time and their infants to help me conduct my research.

Finally, I would like to thank my parents, Rick and Paige Holt, and my brother, Justin Holt, for their love and support. I would especially like to express my deep appreciation to my fiancé, Ally Miller, for her overenthusiasm, companionship, and patience throughout my graduate career, and particularly over the past several weeks. 


\title{
ABSTRACT \\ MECHANISMS RESPONSIBLE FOR THE DEVELOPMENT OF CAUSAL PERCEPTION IN INFANCY
}

\author{
Nicholas A. Holt
}

July 22, 2016

The aim of the current dissertation was to investigate the mechanisms that contribute to the emergence of causal perception in infancy. Previous research suggests that the experience of self-produced causal action may be necessary to promote the development of causal perception (Rakison \& Krogh, 2012). The goal of the current study was two-fold: (1) to further explore the roles of self-produced action, haptic, proprioceptive and visual information, and parental interaction on young infants' understanding of causality. To assess the impact of these factors on infants' causal learning, 41/2-month-olds were randomly assigned to one four conditions. Three of the conditions (Active with Parent Interaction, Active Without Parent Interaction, and Passive with Parent Interaction) provided infants with object-manipulation training in which infants wore "sticky mittens" that allowed them to manipulate Velcro-covered toys. The fourth condition was a no-training control condition. Following training, infants' ability to perceive the difference between causal and non-causal versions of simple collision events (one ball colliding with another) was tested. It was hypothesized that both of the active training conditions would facilitate infants' causal perception, while passive training would produce no effects relative to the control condition. Results demonstrated that 41/2-month-old infants who received no training, and same-aged infants who received passive training that controlled for perceptual aspects of self-produced 
causal action experience (haptic, proprioceptive, and visual information), did not show evidence of causal perception. As hypothesized, active training experience facilitated causal perception in 41/2-month-olds. However, surprisingly, active training only facilitated learning in the condition in which parents were instructed not to interact with their infants. Comparisons of the two active training groups (with and without parent interaction) revealed that the groups did not differ on a number of infant characteristics and behaviors. The results of this study suggest: (1) self-produced causal actions constitute a mechanism by which causal perception arises in infancy, and (2) parental interactions during infants' object explorations may interfere with learning. 
TABLE OF CONTENTS

PAGE

ACKNOWLEDGMENTS ................................................................................ iv

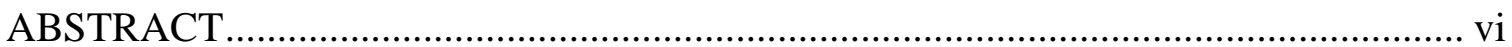

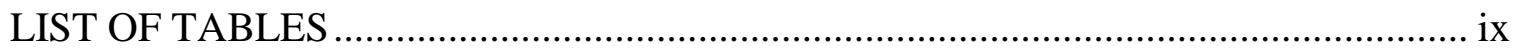

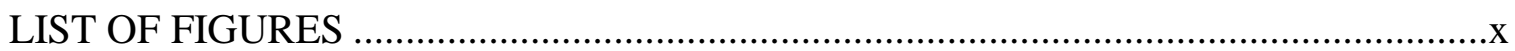

CHAPTER 1: INTRODUCTION AND REVIEW OF LITERATURE ............................1

Perspectives on the Origin of the Ability to Perceive Causes ..............................2

Causal Perception in Infancy ..........................................................................6

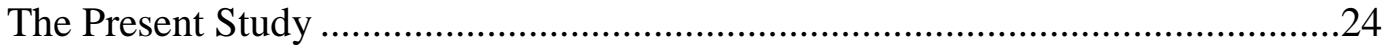

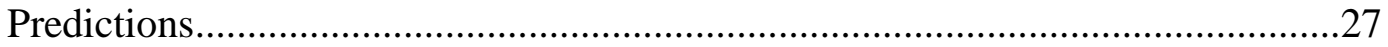

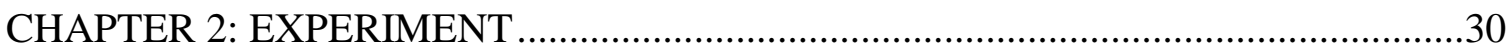

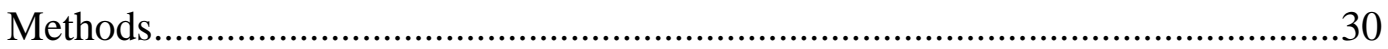

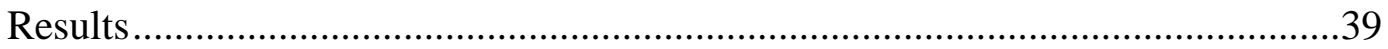

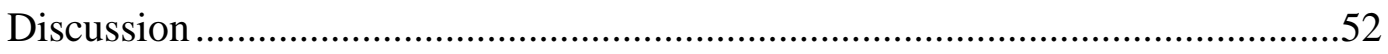

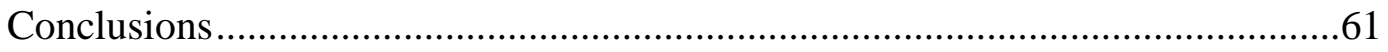

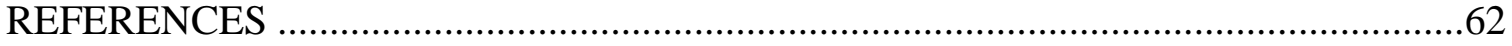

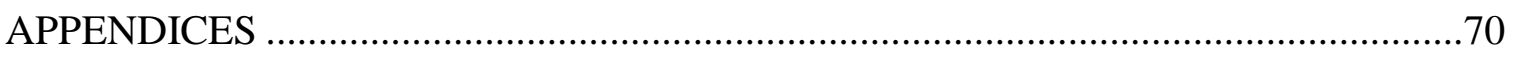

Appendix A: Training Instructions Used for the AI and CTRL Conditions..........70

Appendix B: Training Instructions Used for the PI Condition ............................71

Appendix C: Training Instructions Used for the AN Condition ............................72

Appendix D: Caregiver Perception Rating Scale..............................................73

Appendix E: Reasons that Infants were Excluded from the Final Dataset ............74

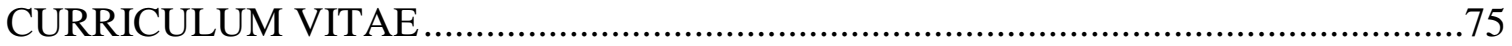




\section{LIST OF TABLES}

TABLE

PAGE

1. Summary statistics for variables used in the preliminary and exploratory analyses .....43

2. Means of parents' ratings of their infants' experience during SM training ..................49

3. Summary and comparisons of measures of infants' object-directed reaching behaviors

during the SM training session between the AN and AI groups .........................51 


\section{LIST OF FIGURES}

$\begin{array}{lll}\text { FIGURE PAGE } & \text { PA }\end{array}$

1. Examples of three types of Michottian launching events …......................................

2. Habituation and test events used in experiment 1A by Leslie (1984).........................

3. Illustration of events used as stimuli in experiments 1 (A), 2 (B), and 3 (C) by

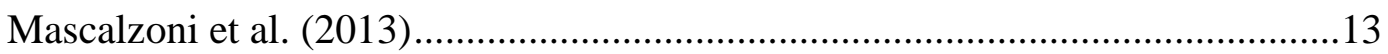

4. Illustration of the habituation event used by Muentener \& Carey (2010). ...................17

5. Habituation and test events from Rakison \& Krogh (2012) ........................................21

6. An infant and his mother participating in the "Sticky Mittens" training task ..............25

7. Distance model of the perceptual differences (distances) between the Michottian launching test events used in the present study .............................................26

8. Visualization of how infants' test trial looking times are interpreted based on the

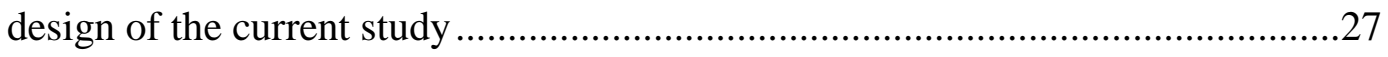

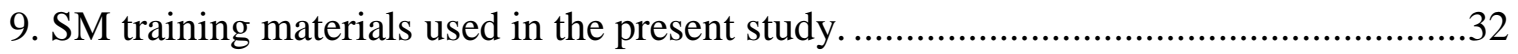

10. Illustration of animations that were used in the causal perception habituation task....36

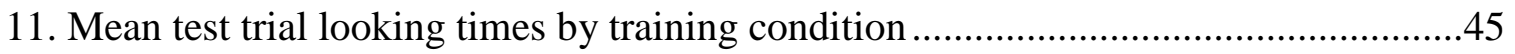




\section{CHAPTER I}

\section{INTRODUCTION \& REVIEW OF LITERATURE}

Causality is a critical concept that allows us to organize our experiences in useful ways and provides the foundation for our understanding of the happenings of the world. A causal relationship exists when the occurrence of one event directly produces the occurrence of another event. When one billiard ball collides with another stationary ball and launches it into motion, people perceive the first ball as causing the second ball to move (Michotte, 1963). This ability to perceive a causal relationship between two events is fundamental to our experience of the world. It is from this basic ability that explanations and interpretations of our experiences are generated and that predictions about the future become possible. Constructing and exploiting knowledge of causality is an essential survival function that allows living things to tailor their actions to the constraints of their environment.

How do we come to perceive the causes of events that occur in the world? More specifically, what are the mechanisms that are responsible for the emergence of causal perception? Based on experiments in adults dating back to the 1940s, the visual impression of causality produced by watching a simple collision event (one ball colliding with another) has traditionally been viewed as a purely perceptual phenomenon that is separate from the process of causal inference (Danks, 2000; Leslie, 1986; Leslie \& Keeble, 1987; Michotte, 1963; Schlottmann \& Shanks, 1992; Scholl \& Tremoulet, 2000). However, the ability to intervene on the world in a causal manner has also received a great deal of attention as a potential mechanism by which causal knowledge is constructed and the ability to perceive causal relationships is derived (Muentener \& 
Carey, 2010; Piaget, 1954; Rakison \& Krogh, 2012; Sloman, 2005, Tenenbaum \& Griffiths, 2003; White, 2007, 2009, 2012). The mechanism(s) by which causal perception arises are not well understood. Historically, the question of whether causal perception is a purely perceptual modular ability or one that derives input from learning that occurs via action experience has been a topic of great debate. The current dissertation aims to trace the ability to perceive cause-and-effect relationships in visual events to its origin in infancy in order to empirically determine whether the ability to causally intervene on objects constitutes a mechanism by which causal perception naturally arises.

\section{Perspectives on the Origin of the Ability to Perceive Causes}

Historically, the prevailing view of causal beliefs in philosophy has been that they are learned and that they involve inference (Hume, 1740/1978). For instance, a person who turns on a faucet believes that doing so will cause water to flow from the tap. According to Hume, until we have observed the effect of turning on a faucet, we can have no a priori knowledge about the consequences of the action. Based on this view, our ability to interpret a collision event in terms of one object causing the movement of a second object requires previous observations of object collisions in order for an expectation or prediction to be generated. Contrary to this view, and beginning with the seminal empirical work of Albert Michotte (1963), vision scientists have argued that causal explanations and beliefs can be generated without prior experience from purely perceptual experiences of causality. Based on an expansive set of experiments exploring adults' perceptions of causality, Michotte advanced a strong case for the idea that, under certain conditions, causal relationships can be perceived automatically from a single 
presentation of any novel visual event. It is from Michotte's foundational studies that modern perspectives on the origin of causal perception have developed.

While causal events may take numerous forms in the natural world, Michotte's (1963) most famous experiments focused on simple collision events. The prototypical causal event examined by Michotte (termed Direct Launching) depicted an object (A) that advanced from left to right and made contact with a second object (B), which began to move immediately after the point of contact. After viewing this event, participants consistently reported that they saw the first object cause the movement of the second object in the direct launching event. Another type of event (termed Delayed Launching) examined by Michotte was identical to the direct launching event except that there was a temporal delay between the initial contact and the movement of the second object (B). Michotte's participants did not report that the first object (A) caused the movement of the second object after viewing the delayed launching event (B). Similarly, a third type of event (termed No Collision or Gap Launching) used by Michotte was identical to the direct launching event except that the first object (A) stopped short of making contact with the second object (B), but the second object (B) began to move immediately (see Figure 1). After viewing the gap launching event, participants did not report that the first object (A) caused the movement of the second object (B). Through these experiments, and many others (over 100 in total), Michotte was able to identify important visual cues that must be present in order to produce the impression of a causal connection between two object movements. Namely, Michotte found that spatial contiguity, where one object appears to contact another object, and temporal contiguity, where an object begins to move immediately after a perceived collision, were both important factors that affected 
whether or not a visual impression of causality was reported by adults. This set of findings has since had a profound impact on the study of causal perception in both adults and infants.

Direct Launching
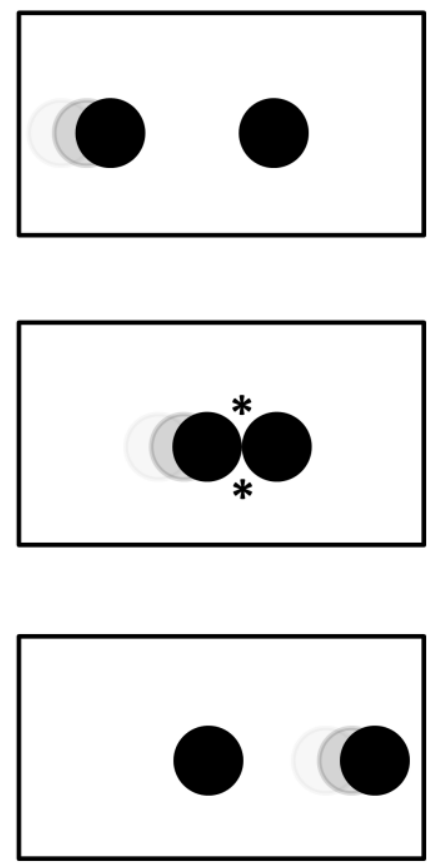

Delayed Launching
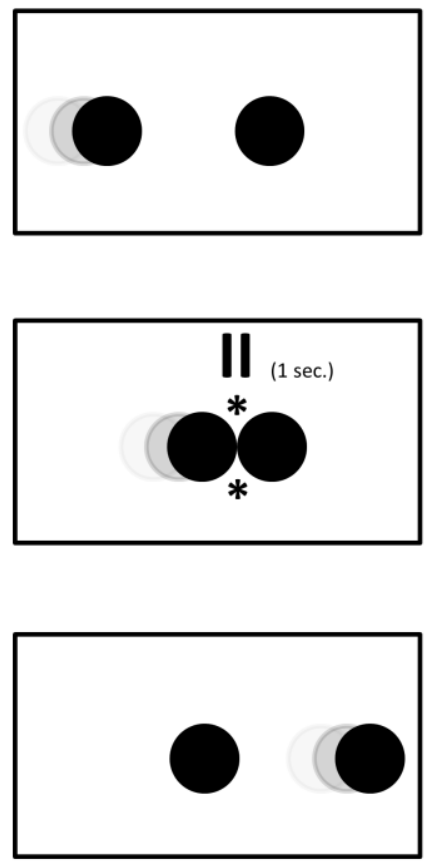

Gap Launching
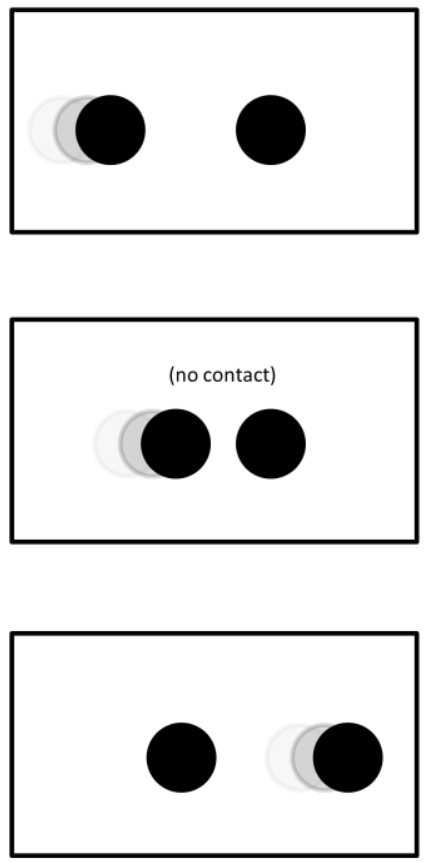

Figure 1. Examples of three types of Michottian launching events.

Based on his large collection of empirical results, Michotte (1963) characterized causal perception as an irresistible and automatic perceptual phenomenon, and hypothesized that causal perception was an ability largely encapsulated from top-down knowledge. This view has been maintained and expanded upon in modern accounts of causal perception (Leslie, 1986; Schlottmann, 2000; Schlottmann \& Shanks, 1992; Scholl \& Tremoulet, 2000). However, mounting evidence has demonstrated that top-down knowledge about objects influences the impression of causality produced by watching a collision (launching) event. Namely, it has been noted that an impression of force seems 
to accompany the impression of causality produced by a visual launching event (White, 2007, 2009).

When we act on objects, we perceive that we apply force (or effort) to cause a desired effect. Anecdotally, when we view a bowling ball knock over bowling pins, our dominant perception is that the ball exerted force onto the pins, not that the pins failed to resist the ball. In this way, White (2009) notes that our interpretation of causal events is unidirectional (i.e., we do not perceive that the object receiving the action exerted an equal and opposite force at the point of collision). This notion is supported by the fact that in not one of Michotte's (1963) experiments did participants suggest that object B stopped the movement of object A. Recent studies have found additional evidence for an asymmetrical interpretation of the direction of force in causal events (White, 2006, 2007). For example, White (2007) explicitly asked adults to make a judgement about the amount of force exerted on object B by object A (and vice versa) while watching a series of launching events. Participants consistently demonstrated an asymmetrical bias to rate the force imparted by the object (A) that caused the collision as greater than the force imparted by the object (B) that received the collision. Interestingly, participants' judgements of the force exerted by object B were consistently near zero even when object A appeared to "bounce" backward from the point of collision. White (2009) has proposed a theory that this asymmetry, and the perception of causality more generally, is governed by the interpretation of events in terms of our previous haptic experiences. In White's view, perceptions of collisions are automatically compared to representations of previous experiences that involved physically exerting force on objects. When we interact causally with objects, we experience a feeling of our own effort. The feeling involved in this type 
of action is referred to commonly as a sense of agency. When we watch a collision event, White suggests that we generalize our experiences of agency to interpret the force that object A imparts onto object B to cause it to move. Thus, for White, the origin of causal perception lies in our agentive experiences causally manipulating objects. Highly similar hypotheses about the origin of causal impressions have been advanced in slightly different forms by several other notable thinkers (James, 1890; Maine de Biran, in Michotte, 1963; Piaget, 1954).

The idea that visual impressions of causality involve inferences about objects that are derived from physical experience is in direct competition with the theory advanced by Michotte (1963) and other perception scientists that causal perception is largely uninfluenced by top-down factors. In addition, Michotte believed that causal perception was an innate ability. However, the competing hypothesis presented by White (2009) suggests that causal perception involves a learning component. One decisive way to determine whether the perceptual account proposed by Michotte or the experience-based account proposed by White and others is correct is to examine how infants come to perceive the causal relations between objects in collision events.

\section{Causal Perception in Infancy}

Traditionally, research on causal perception in infancy has sought to settle the debate over whether or not the ability to perceive causation from launching events is innate. Building off of Michotte's ideas, Leslie (1982) sought to test whether infants were sensitive to the perceptual differences between various types of launching events. However, since Leslie's first studies of causal perception in infancy, researchers have found evidence against Michotte's claims. The sections that follow systematically 
demonstrate that causal perception: (1) is probably not innate because it emerges in distinct stanges between 4 and 6 months of age (Cohen \& Amsel, 1998), and (2) is not encapsulated from top-down influences because physical (size) and dispositional (agent or patient) features of the objects involved in causal events affect infants' expectations and interpretations of these events (Kotovsky \& Baillargeon, 1998; Muentener \& Carey, 2010). Finally, this review will evaluate evidence in favor of the idea that causal perception originates from self-produced experiences manipulating objects in infancy.

\section{Is Causal Perception Innate?}

Early investigations of Infants' Causal Perception. Alan Leslie was the first to conduct systematic investigations of causal perception in infancy. In doing so, he adapted Michotte's (1963) methods to test infants' sensitivity to different versions of launching events. The primary method of investigating causal perception in infancy involves habituating (i.e., presenting a stimulus repeatedly until infants begin to lose interest) infants to one type of Michottian event (direct, delayed, or gap launching) and then measuring the degree to which infants dishabituate or recover interest toward the other types of events. If infants recover interest toward an event that contains a conceptual difference (i.e., a difference in causal structure), but not toward an event of the same conceptual category that is perceptually different, then it is inferred that they are capable of differentiating causal from non-causal events.

Studies using variations of this method have found that the ability to differentiate causal from non-causal events emerges early in the second half of the first year of life (Cohen \& Amsel, 1998; Leslie, 1984). Leslie (1984) conducted a series of experiments with $61 / 2$-month-olds in order to examine whether infants perceive causality when viewing 
direct launching events. In Experiment 1A, Leslie habituated infants to either a direct launching event that involved two different colored objects or an event in which a single object moved from left to right across a screen (see Figure 2). During the test phase, infants' response to the same event played in reverse was measured. Leslie found that infants in the direct launching condition recovered interest to the reversed event whereas infants in the continuous motion condition did not. In Experiment 1B, infants were habituated to either a direct launching event that involved two different colored objects or an event in which a single object moved from left to right across a screen and changed from one color to another halfway through the continuous movement. Infants' responses to the opposite type of event (direct launching or continuous with color change) were measured during the test phase. Infants in both habituation conditions recovered interest to the opposite type of event at test, which indicated that $61 / 2$-month-olds could tell the difference between a direct launching event and a single object that changed color halfway through a continuous movement. These findings suggest that infants are able to represent two distinct objects and two distinct movements while viewing a direct launching event. 


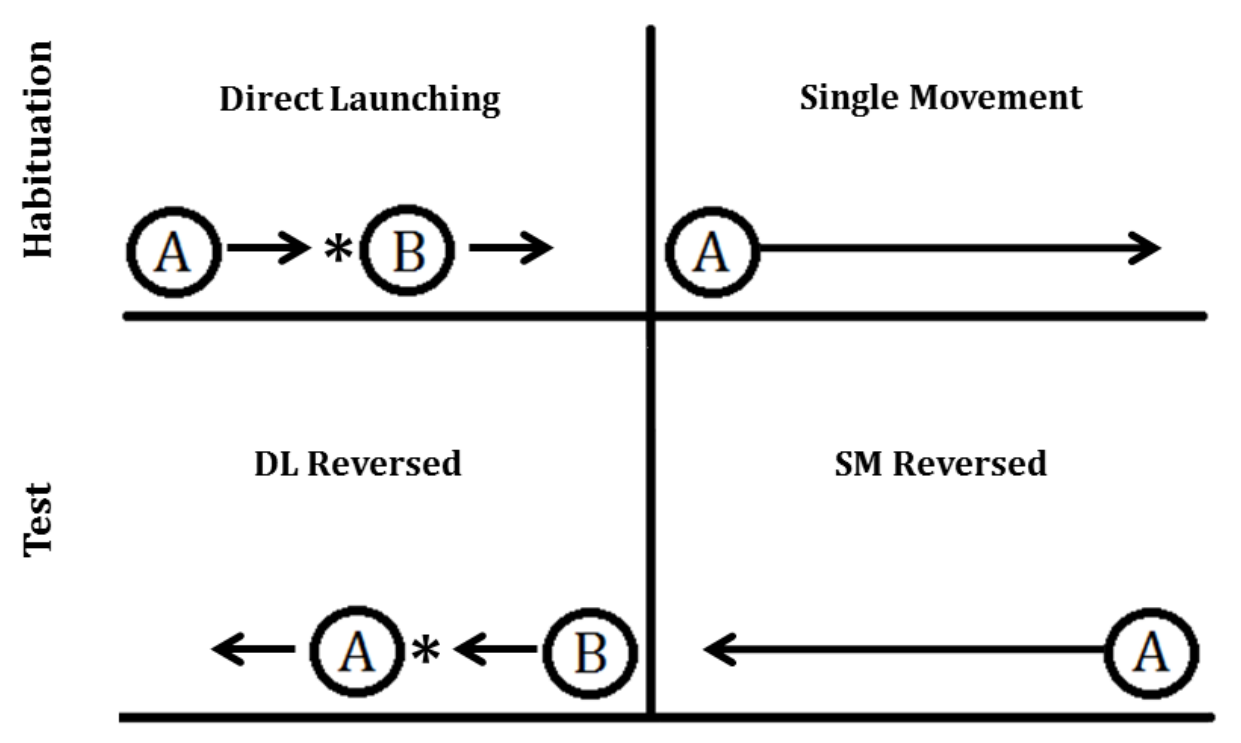

Figure 2. Habituation and test events used in Experiment 1A by Leslie (1984).

Building upon these findings, Leslie (1984) conducted another experiment to determine whether $61 / 2$-month-old infants are capable of responding on the basis of a causal/non-causal distinction to variations of launching events. In this experiment (Experiment 2), Leslie habituated infants to either a direct launching (causal) or delayed launching (non-causal) event. In the direct launching condition, infants were tested on a delayed-gap launching (non-causal) event, which is an event that combines the onesecond pause of the delay event with the spatial gap from the gap event. In the delayed launching condition, infants were tested on a gap launching event (non-causal). Infants appeared to recover interest toward the test trial in both conditions, but the magnitude of the recovery was significantly greater for those infants who were habituated to the causal (direct launching) event and then tested on the non-causal (delayed-gap launching) event. Leslie interpreted this pattern of results as evidence that $61 / 2$-month-olds can perceive and encode information about causality. Leslie went on to suggest that causal perception in 
infancy is the result of an innate perceptual module that operates without experiencedriven learning about causality (Leslie, 1988; 1995).

In an attempt to further explore the results obtained by Leslie (1984), Oakes and Cohen (1990) conducted one of the first studies to examine how causal perception develops over the first year of life. Oakes and Cohen (1990) replicated Leslie's (1984) basic experimental design but tested 6- and 10-month-olds. In addition, Oakes and Cohen (1990) opted to use images of realistic toy vehicles as their stimuli in lieu of red and green blocks and expanded their investigation to include three different conditions in which infants were habituated to either a direct, delayed, or gap launching event. Following the habituation procedure, infants were tested on all three of the events. This more elaborate design allowed for the researchers to more precisely investigate whether infants test responses are driven by perceptual differences between the events, or by an understanding of the conceptual differences between causal and non-causal events. Results obtained in the 10-month-old group demonstrated that, when habituated to a direct launching event, infants showed an increase in looking time toward both the gap and delayed launching events. However, 10-month-olds habituated to either type of noncausal event only showed increased interest toward the direct launching event at test. This evidence indicates that 10-month-olds responded solely on the basis of causality, as those infants who were habituated to a non-causal event generalized their habituation to a novel non-causal event. However, the 6-month-olds tested in the experiment showed no evidence of causal perception whatsoever. Oakes and Cohen interpreted this null finding with 6-month-olds as evidence that stimulus complexity may overwhelm infants' ability to process the events properly. 
To further examine how causal perception may develop, Cohen and Amsel (1998) used simpler stimuli and tested 4-, 51/2-, and 61/4- month-olds on a task replicated from Leslie (1984) but with the additional within-subjects test trials employed by Oakes and Cohen (1990). Again, in this study, infants were randomly assigned to one of three habituation conditions: direct launching, delayed launching, or gap launching. Following habitation, each infant viewed all three types of events on separate test trials that were counterbalanced to prevent order effects. The results of this study convincingly demonstrate a distinct developmental progression. Cohen and Amsel found that although the $6^{1 / 4-m o n t h-o l d s ~ r e p l i c a t e d ~ L e s l i e ' s ~(1984) ~ f i n d i n g s ~ a n d ~ d i s h a b i t u a t e d ~ o n ~ t h e ~ b a s i s ~ o f ~}$ separate causal/non-causal event categories, the 5 1/2-month-olds habituated to the noncausal events dishabituated equally to the opposite non-causal event and the causal event, indicating that they responded based on the spatiotemporal differences between the events. Furthermore, the 4-month-olds dishabituated solely to the differences in the continuous movement between the events. Another study with even younger infants (31/2month-olds) has confirmed that very young infants respond only to the differences in continuous motion between launching events (Desrochers, 1999). Cohen and Amsel suggested that these findings point to the conclusion that infants are able to encode information about the temporal differences between launching events early on and then, after some development has occurred, they begin to encode information about the temporal and spatial differences between the events. They also suggested that later, at around 6 to $6 \frac{1}{2}$ months of age, infants are able to integrate information about the spatial and temporal properties of launching events into a representation that allows a distinction to be made between causal and non-causal events. 
Causal Perception in Newborns? The studies discussed above provide evidence against Michotte's (1963) suggestion that infants are born with an innate predisposition to perceive direct launching events as causal. Another way to determine whether causal perception is innate in origin, however, is to look for evidence that newborns can reliably discriminate between causal and non-causal events. In the only study to examine causal perception at birth, Mascalzoni, Regolin, Vallortigara, and Simion (2013) recently measured newborns' visual preference for variations of Michottian events by showing them two different types of launching events side-by-side over two counterbalanced trials. Results of their first experiment showed that 10 out of 12 newborns looked longer toward a launching event than a delay event. Authors claim that the results of this experiment "favour the idea that naïve newborns are able to perceive physical causality in a launching event." However, as Cohen \& Amsel (1998) made clear, prior to being able to discriminate between Michottian events on the basis of causality, infants discriminate the events first on the basis of continuous motion. In fact, Cohen and Amsel explicitly note that a simple preference for the causal launching event prior to $5 \frac{1}{2}$ months of age may potentially be explained by "entrainment to continuous movement."

In two subsequent experiments Mascalzoni et al. examined newborns' preference for similar events with different manipulations to reject the possibility that participants responded preferentially to continuous motion present in their first experiment. Experiment 2 presented infants with a direct and delayed launching event side-by-side. However, in this experiment the trajectory of the second object in both events was altered by $90^{\circ}$ (see Figure 3). The results of this experiment showed that 10 out of 12 infants looked longer at the delayed launching event. Authors concluded that newborns preferred 
temporal discontinuity in this case because they do not have an implicit preference for continuity of motion. Thus, they claim that this pattern of results "refutes the possibility that newborns' preference for the launching event found in Experiment 1 might have been due to a mere preference for temporal continuity." However, as Michotte (1963) demonstrated in adults, altering the trajectory of a direct launching event by as little as $25^{\circ}$ is enough to diminish the impression of causality considerably in adults. Similarly, a $45^{\circ}$ change in trajectory disrupts causal perception in infants younger than 10 months of age (Oakes, 1994). Thus, it would seem that if newborns possess an innate disposition to attend to events involving physical causality the correct prediction for Experiment 2 should be that infants would show no preference for either of the events, as both should be interpreted as non-causal.
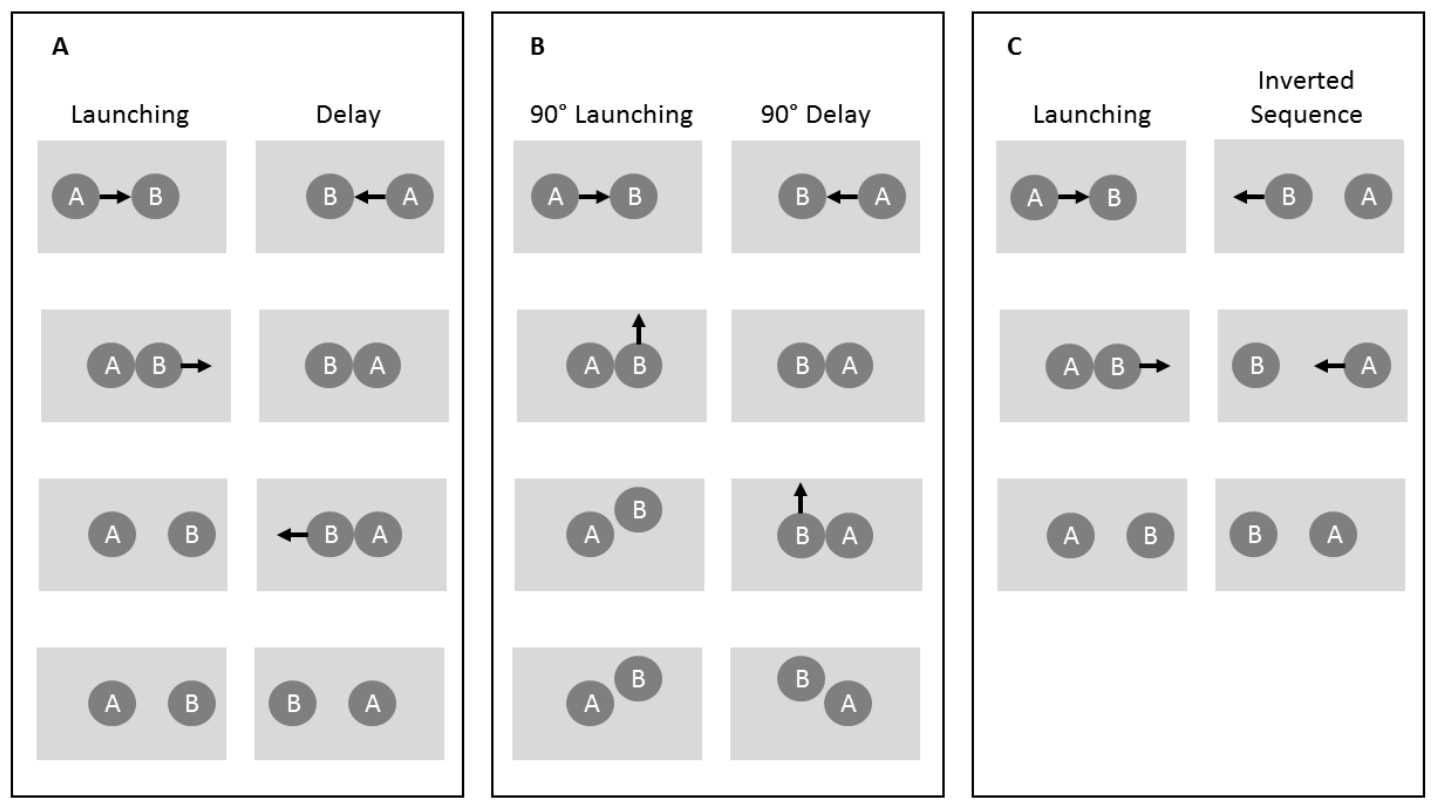

Figure 3. Illustration of events used as stimuli in Experiments 1 (A), 2 (B), and 3 (C) reported in Mascalzoni et al. (2013). Figure reconstructed from original report. 
In the third experiment reported by Mascalzoni et al. (2013), newborns viewed a direct launching event and an "inverted-sequence" of the same event (see Figure 5). In the inverted sequence object B first moved from the center of the screen toward one side, followed immediately by the movement of object A from the opposite side toward the center. Authors report that 12 out of 16 infants looked longer at the direct launching event than the inverted sequence. This result was interpreted as evidence that newborns discriminate between events that differ in the order of object displacement. Because newborns preferred the causal event this result was also taken as confirmation of the findings from Experiment 1. However, as in Experiment 1, this set of contrasting events does not control for the possibility that newborns are simply tracking the continuous movement of the direct launching event.

In sum, the set of studies reported by Mascalzoni et al. (2013) falls short of demonstrating the existence of an innate ability to represent causal relations. The use of preference as a measure is problematic in that it remains unclear how a simple visual preference provides a measure of causal perception. Oakes and Cohen (1990), for example, showed infants direct, gap, and delayed launching events, and a fourth event that depicted the simple continuous movement of one object, and found no significant visual preferences for any of the events at 6 or 10 months of age. Additionally, the habituation studies reviewed above demonstrate that developmental differences exist in infants' causal perception (i.e., Cohen \& Amsel, 1998; Oakes \& Cohen, 1990), which does not support the authors' central claim that newborns can perceive a direct launching event as causal. Thus, currently, evidence suggests that the ability to perceive causality in launching events starts to develop sometime between 4 and 6 months of age. 


\section{The Case Against Encapsulated Causal Perception in Infancy}

Evidence presented thus far has suggested that causal perception is probably not an innate ability. However, Michotte (1963) and others have also claimed that causal perception is encapsulated from top-down influences. At least two studies from the infant literature provide clear evidence that, in infancy, causal perception is influenced by topdown information about the objects involved in visual collision events. First, in a study

conducted by Kotovsky and Baillargeon (1998), 51/2- and 61/2-month-olds were habituated to a launching event in which a cylinder rolled down a hill and collided with a "bug" object, which in turn moved away from the point of collision immediately following the impact and came to rest in the middle of the scene. Following habituation, infants were tested using versions of the events in which the cylinder was either larger or smaller than the one used in the original sequence, and following contact in the test trials the bug always moved significantly further (i.e. to the far end of the scene). Although results from the younger group are difficult to interpret, it appears that $61 / 2$-month-olds dishabituated only to the test event in which the smaller object caused an increase in the post-collision distance traveled by the bug, indicating that their representation of a collision is influenced to some degree by the size of the objects involved. If causal perception were encapsulated from top-down influence, it would seem that the output of the mechanism should not be affected by physical attributes such as size. Thus, Kotovosky \& Baillargeon's (1998) findings corroborate White's (2009) theory that a mental simulation of contact force actually underlies causal perception.

Another more recent set of five experiments also provides consistent evidence that refutes the encapsulated perceptual account of causal perception in infancy. 
Muentener and Carey (2010) contend that the experience-based account of the origin of causal perception theorized by White (2009) and Piaget (1954) generates two important predictions that contradict the Michottian account: (1) infants' earliest understanding of causality should be based on perceiving causal objects as intentional agents because the concept of causality originates from experiences of causal agency, and (2) infants' earliest causal perception abilities should not be restricted to motion events because when acting as causal agents, infants do not simply cause objects to move, they can also cause state changes.

In order to test these predictions, Muentener and Carey (2010) habituated 8month-olds to an ambiguous motion event. During the habituation event, a train entered the field of view on a stage, and then advanced toward a red box that was partially occluded by a black screen in the middle of the stage area. As it advanced, the train moved completely behind the screen, and then the red box began to move in the same direction toward the right side of the stage (see Figure 4). Importantly, no collision between the train and the red box was made visible to infants at any point during habituation. During the test phase, infants saw both a direct launching version and a gap launching version of the habituation event, but the occluding screen was not present. When the key area of the event was unoccluded during the test phase, infants looked significantly longer at the gap launching version of the habituation event. This finding suggests that by 8 months infants are able to infer a causal collision between two objects when the collision itself is occluded and not directly perceived (see also Ball, 1973; Kosugi, Ishida, \& Fujita, 2003; Muentener \& Carey, 2006; Spelke, Phillips and Woodward, 1995). 


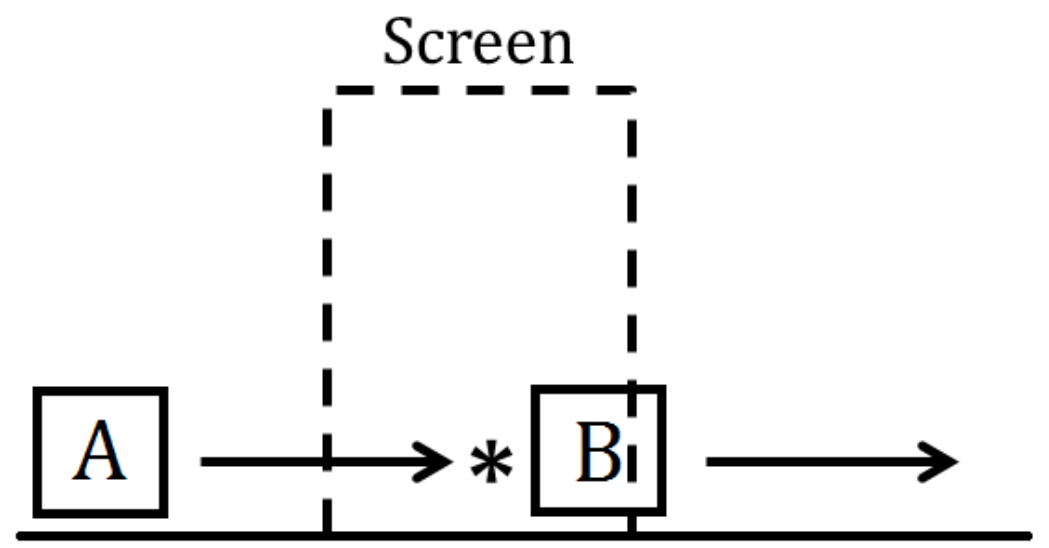

Figure 4. Schematic illustration of the habituation event used by Muentener \& Carey (2010).

In Experiment 2, Muentener and Carey (2010) showed infants two types of causal state-change events in order to determine whether infants infer causality from events that involve physical state changes, but do not involve visual collisions. In one event a train moved from left to right toward a white box partially occluded by a screen. When the train became fully occluded by the screen, the box changed color from white to red. The second type of event was identical except that the box was red and after the train was occluded fully by the screen the box broke apart into pieces. During the test phase, infants saw both a direct launching version and a gap launching version of the habituation event, but the occluding screen was not present. Infants looking behavior at test was identical for both versions of the event across both event types. However, in three nearly identical additional experiments, Muentener and Carey showed that when a human hand or an agentive object with a face replaces the toy train as the causal agent in the events, infants dishabituate to the gap launching version of the event. This finding indicates that although infants are not sensitive to the causal connection present in an event where an 
inanimate object causes a state change, by 8 months, infants infer a causal state change when the causal object can be easily identified as an agent. Furthermore, by 12 months, infants understand that inanimate objects (such as a toy train or a ball) can only cause state changes involving randomness and disorder, while agents (such as hands or objects

with faces) are able to cause state changes that are orderly (Newman, Keil, Kuhlmeier, \& Wynn, 2010). These results suggest that the dispositional features (agent or inanimate object) of the objects involved in causal events, as well as the type of causal event (collision or state change) interact to produce different causal inferences. These results seem to refute Michotte's idea that causal perception is produced by an encapsulated, purely perceptual process. However, the experience-based account advanced by White (2009) does not simply predict that causal perception is influenced by top-down knowledge. The account proposed by White and others explicitly predicts that causal perception involves a mental simulation of the force involved in a collision that is based on self-produced agentive object interactions. The last step needed to fully dissolve the Michottian perceptual account and sufficiently endorse the experience-based account, then, is to demonstrate that the earliest causal inferences about visual events are directly facilitated by self-produced causal interactions with objects.

\section{The Role of Self-produced Action in the Development of Causal Perception}

The findings reviewed above point to the conclusion that although infants become able to distinguish events based on their spatial and temporal differences between 4 and $5 \frac{1}{2}$ months of age, causal perception does not emerge until around 6 months of age. However, the factors that influence the emergence and maturation of the ability to distinguish causal and non-causal events are not well understood. The experience-based 
account of Piaget (1954) suggests that infants gradually construct representations of causes and their effects through repeated actions. Recent efforts to corroborate this account have met some success.

The effects of infants' own actions on their cognitive development have been investigated using a training paradigm commonly referred to as "Sticky Mittens" (SM) training (Needham, Barrett, \& Peterman, 2002). This training task involves fitting prereaching infants with Velcro-covered mittens that allow them to grasp Velcro-covered objects. Thus, the task allows young infants to effectively manipulate objects at an age prior to their natural development of this ability. The SM task has been used to demonstrate that self-produced actions facilitate the emergence of abilities across a host of cognitive domains early in development. For example, infants who receive SM training demonstrate early changes in interest toward faces (Libertus \& Needham, 2011; 2014), increases in object-directed behaviors (Libertus \& Needham, 2011; Needham, Barrett, \& Peterman, 2002), development of three-dimensional object completion (Soska, Adolph \& Johnson, 2010), and development of goal perception (Gerson \& Woodward, 2013; Sommerville, Woodward, \& Needham, 2005; Sommerville, Hildebrand \& Crane, 2008).

Rakison and Krogh (2012) recently conducted a SM training study to examine the effects of self-produced action on causal perception in 4⿳⺈/2-month-olds. They hypothesized that providing 41/2-month-olds with relevant causal action experience in the lab would facilitate their causal understanding. In Experiment 1, infants were divided into two training groups: a causal action group and a non-causal action group. Infants in the causal action group were fitted with Velcro mittens that allowed them to manipulate or 
"pick up" Velcro covered balls. Each parent was instructed to keep their infant on their lap and to not interact with the infant in any other way while the child interacted with the Velcro-covered toys for 3 minutes. The non-causal action group completed an identical task in which the mittens were not covered in Velcro and the balls were glued to the tray so that they could not be manipulated. Across both conditions, the mittens were red and the toy balls were green. Upon completing the training phase, infants' causal perception was measured. Infants were habituated to a prototypical direct launching event in which a red ball contacted a green ball. These colors were designed to be consistent with the colors of the mittens and balls used in the training phase. Infants were then tested using three different reversed versions of the launching event: (1) a direct launching event in which the causal roles were familiar, (2) a "causal switch" direct launching event in which the causal roles of the objects were reversed (green contacted red), and (3) a noncausal gap launching event (see Figure 5). Results of this experiment demonstrated that infants in the sticky mittens condition dishabituated to the causal switch event and the non-causal event indicating that they were sensitive to changes in causality. In contrast, the control group dishabituated to all of the test events, indicating that they responded predominantly to the reversal of continuous movement in the events. 


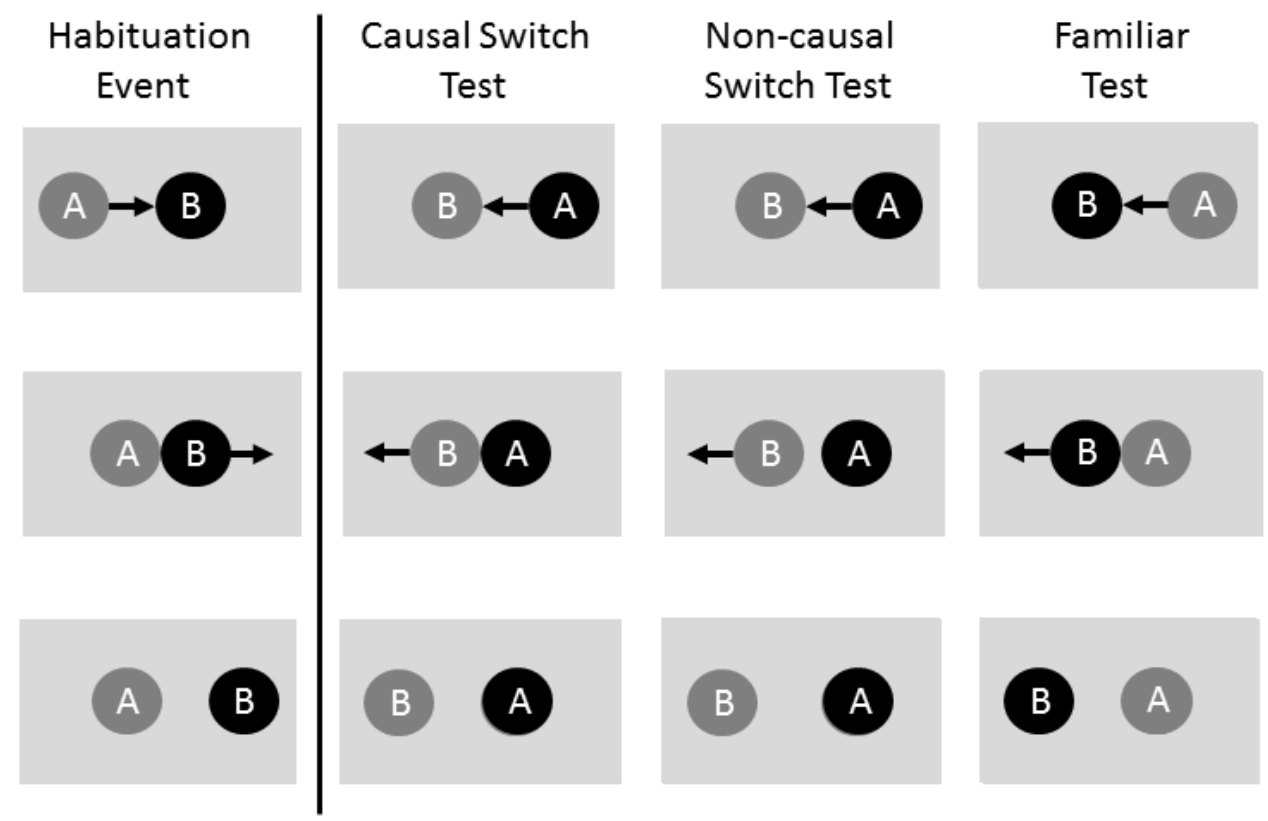

Figure 5. Habituation and test events from Rakison and Krogh (2012). Figure reconstructed from original publication.

Based on these findings, Rakison and Krogh (2012) attributed the emergence of causal perception to infants' development of the ability to causally interact with objects. These results suggest that causal actions may be important for developing causal perception, but more evidence is needed before that conclusion can be made. There are several other factors that need to be considered.

First, causal action experience contains rich, multimodal contingent input, producing feelings of causal or volitional effort as well as certain sights and haptic sensations (e.g. information about force, object weight, etc.). It is currently unknown how the sensation of agency, haptic input, and visual input are related to the emergence of causal perception. The two training conditions used by Rakison and Krogh not only contained completely different experiences of causality, they were associated with different visual, haptic, and proprioceptive experiences as well. During the causal SM 
training task, infants caused the objects to move, but they also felt and saw the objects moving contingently with their actions. In the control task, infants did not make the objects move. Consequently, they also did not get to see or feel the green balls move contingently with the red mittens. In fact, they never saw the objects move at all. The control training condition used in Rakison and Krogh's study therefore limits how the results can be interpreted. To better understand the role of self-produced causal action experience in the emergence of causal perception, infants' experience of causal agency should be manipulated while contingent haptic, proprioceptive, and visual information remain constant.

Second, Rakison and Krogh's study, while tightly controlled, also failed to take the role of parental interaction into account. One crucial detail of their study that has been overlooked is that parents in both training conditions were instructed not to interact at all with their infants during training (D. Rakison, personal communication, April 22, 2016). In a more naturalistic setting outside of the lab, infants likely spend a great deal of time learning in the context of parent-child interactions. It has long been known that the social environment in which learning takes place can play an important role in learning outcomes and task performance (Vygotsky, 1987). In fact, the SM task is a classic example of Vygotskian scaffolding because the task provides infants with a means to demonstrate a behavior (grasping) that is just beyond their developmental level and parents are typically allowed to provide social scaffolding through encouragement as well (Libertus \& Needham, 2011, 2014). For example, Libertus and Needham (2010, 2014) examined the independent and combined effects of self-produced actions and parental encouragement (eye-contact, pointing, verbal cues, etc.) on infants subsequent reaching 
behaviors and preference for faces. They found that neither self-produced actions nor parental encouragement during the object exploration training tasks were sufficient to facilitate increases in independent reaching behaviors or a robust preference for human faces. However, the combination of parental encouragement and self-produced action experience did facilitate increases on both measures. Thus, social factors related to pedagogy (i.e. parental encouragement) may constitute a mechanism that facilitates the development of causal perception.

Putting it all together, it is unknown how passive experiences of causal object manipulations may contribute to the emergence of causal perception in infancy, but there is reason to believe that if passive experience were to work, it would be more likely to do so in the context of naturalistic parent-child interactions (e.g., Libertus \& Needham, 2014). Also, Rakison and Krogh (2012) found that their non-causal training condition did not produce causal perception. This suggests that non-causal actions in the absence of parental encouragement do not facilitate causal perception. However, it is possible that infants may learn about causality from non-agentive experiences in the context of a more naturalistic learning environment. Similarly, if causal perception originates from contingent haptic, proprioceptive and visual information, providing infants with passive object exploration experience that contains strong perceptual cues about causality could facilitate causal perception. Thus, a combination of passive object manipulation experience that contains rich contingent haptic, proprioceptive, and visual cues and parental interactions that are encouraging and motivating during training could potentially facilitate infants' learning about causality. If this were the case, then the experience of causal agency could be ruled out definitively as the origin of causal 
perception, and the contingent haptic, proprioceptive, and visual information that result from self-produced causal object manipulation could be implicated as the source of the ability to infer causality from visual collision events.

\section{The Present Study}

The primary purpose of this dissertation project was to examine the unique contribution of self-produced causal action experience during SM training to young infants' learning about the causal interactions between objects. The goal of the current study was two-fold: (1) to determine whether the self-produced nature of infants' object interactions during active SM training is the driving mechanism behind the task's facilitative effects, or whether perceptual aspects (haptic, proprioceptive, visual) of active experience are sufficient for learning to occur, and (2) to assess the impact of active experience on infants' causal learning in a more naturalistic situation. To address the first goal, infants' causal perception learning outcomes were compared after infants received either active or passive SM training that controlled for contingent perceptual experiences (haptic, proprioceptive, and visual). The second goal was assessed by comparing infants' learning outcomes following active SM training in which parents were either restricted from interacting or encouraged to interact with their infants throughout the task.

\section{Design}

In the present study, 4 1/2-month-old infants received a brief in-lab SM training experience (see Figure 6) that was modeled after the design of Rakison and Krogh (2012) and completed a causal perception habituation task modeled after the task used by Cohen and Amsel (1998). To address the aims of the study, infants were randomly assigned to one of three SM training conditions (Passive/Interaction, Active/Interaction, Active/No Interaction) or a control condition. Infants in the three SM training conditions completed 
the habituation task immediately following training to assess the facilitative effects of the various SM training manipulations. Infants in the control condition received no training prior to completing the causal perception habituation task; the control condition was included to get a baseline measure of 4-1/2-month-olds' performance on the causal perception habituation task.
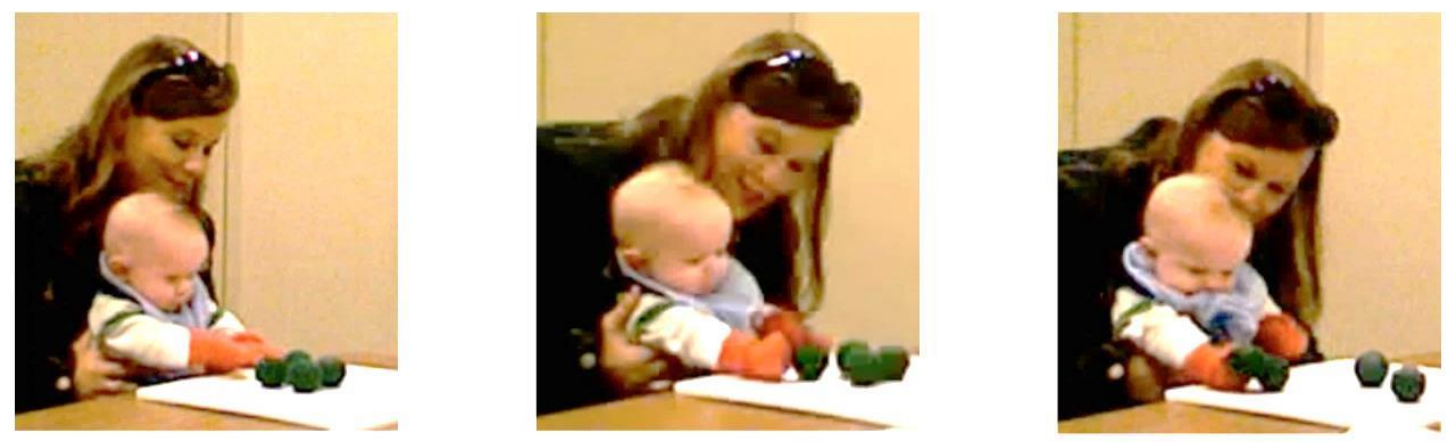

Figure 6. An infant and his mother participating in a "Sticky Mittens" training task.

Infants' perception of causality was tested using a visual habituation paradigm based on Cohen and Amsel (1998). ${ }^{1}$ Infants were habituated to either a non-causal delay or gap version of a typical Michottian launching event. After the habituation phase, three test trials were presented: (1) familiar, (2) non-causal, and (3) causal. The overall pattern of looking times across the three test trials was used to determine whether infants responded to perceptual differences between the events, or on the basis of causality. Importantly, the causal and non-causal events both differed perceptually from the familiar

\footnotetext{
${ }^{1}$ The habituation task used by Cohen and Amsel (1998) was chosen because it contains a true "familiar" test trial, which allows for direct comparisons between the familiar, noncausal, and causal test trials. Including a truly familiar trial during test is considered a best practice in the use of habituation paradigms (Cohen, 2004; Oakes, 2010).
} 
event; the familiar and non-causal events differed from one another along two perceptual dimensions (spatial and temporal), and the familiar and causal events differed along one perceptual dimension (see Figure 7). Infants were judged to respond to the perceptual differences between the test events if they produced looking times that were significantly greater for both the causal and non-causal trials compared to the familiar trial (see Figure 8). Alternatively, infants were judged to successfully perceive causality (i.e., interpret the causal event as categorically different from the familiar event, but interpret the noncausal event as categorically similar to the familiar event) if they produced a looking time to the causal event that was significantly greater than looking time toward the familiar event, while responding similarly to the familiar and non-causal events.

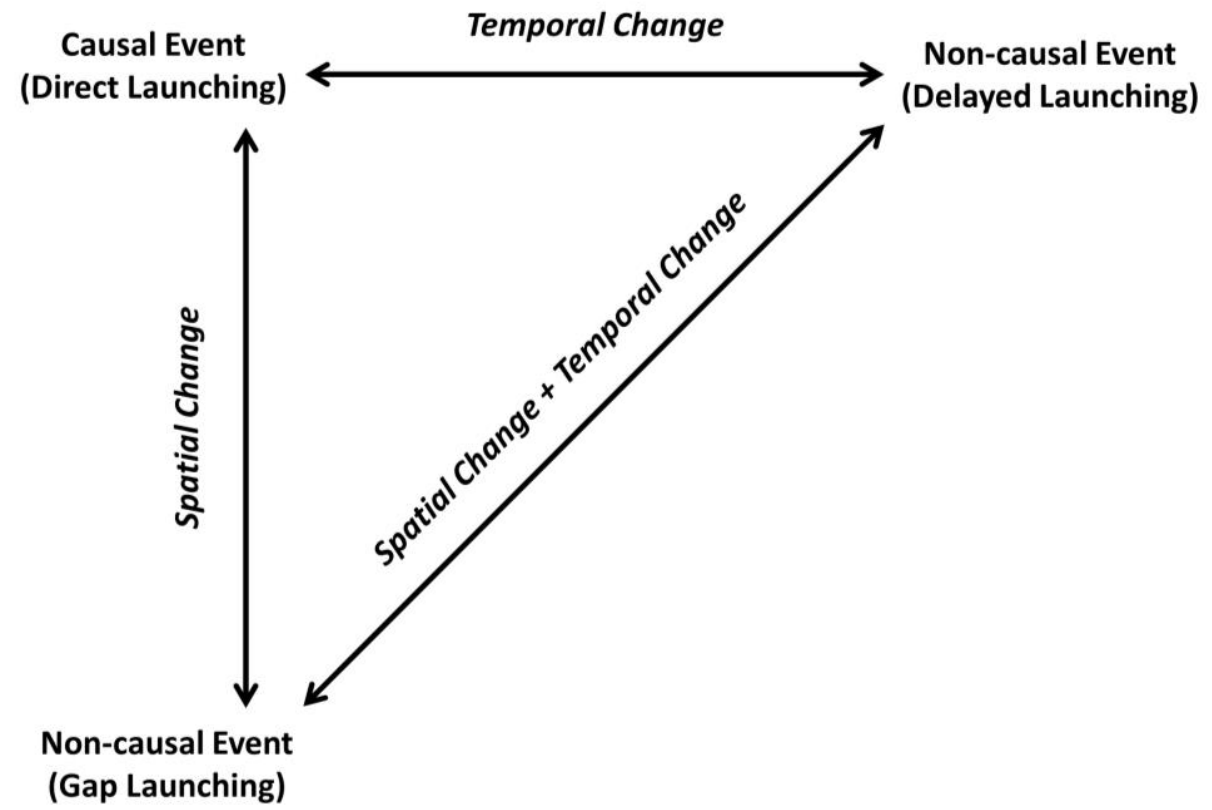

Figure 7. Distance model of the perceptual differences (distances) between the Michottian launching test events used in the present study (adapted from Cohen, Amsel, Redford, \& Cassasola, 1998). 


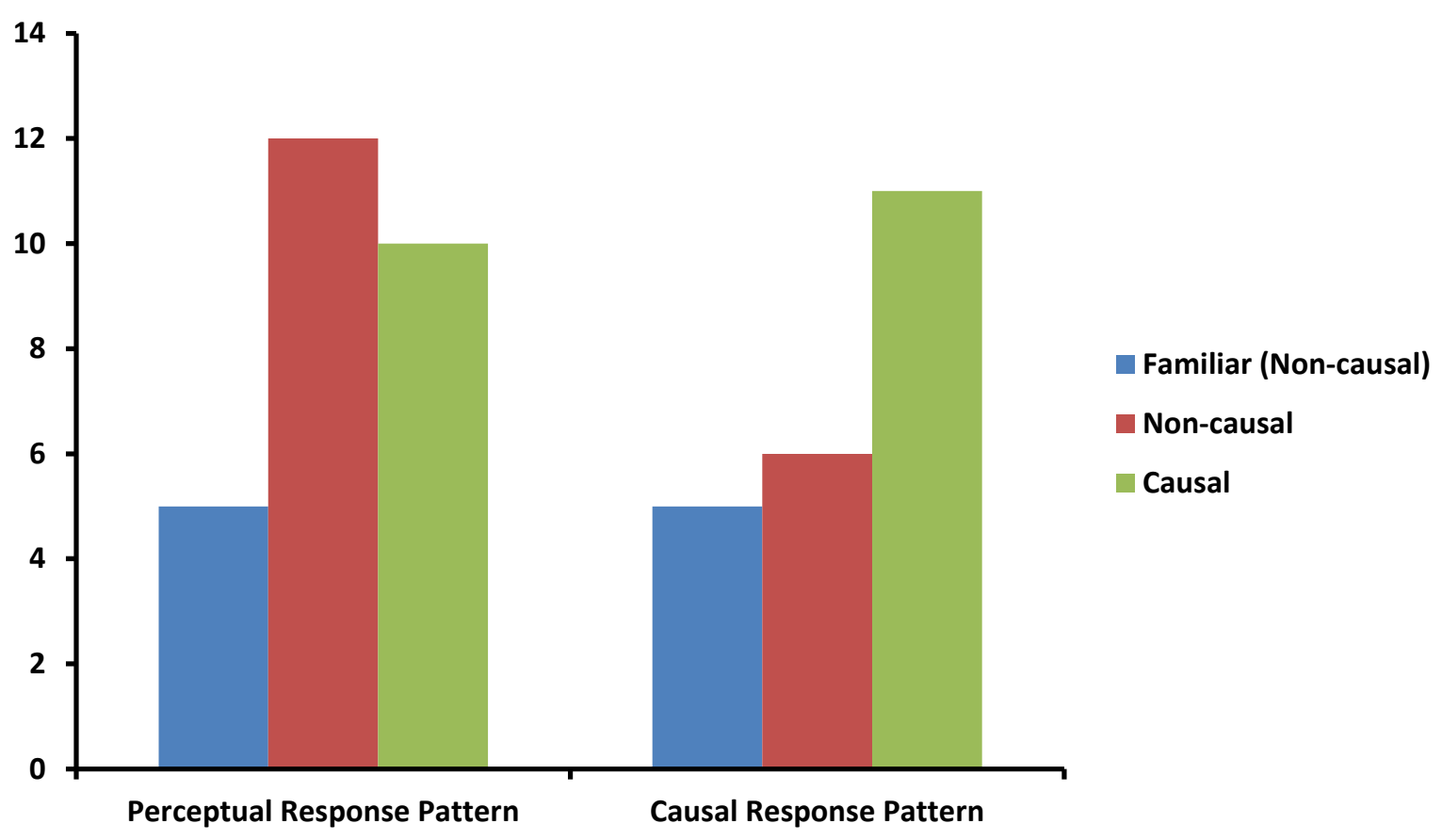

Figure 8. Visualization of how infants' test trial looking times are interpreted based on the design of the current study.

\section{Predictions}

It was hypothesized that infants in the no training (control) condition would demonstrate a perceptual response pattern during the causal perception habituation experiment, replicating previous studies of infants' causal perception for this age range (Desrochers, 1999, Cohen \& Amsel, 1998).

Regarding the first goal of the current study, which was to determine the role of self-produced action versus perceptual/haptic factors in facilitating causal perception, it was hypothesized that the self-produced nature of infants' object interactions during active SM training would be the primary mechanism that would facilitate causal perception. It was expected that only those infants who received a form of active SM training would successfully distinguish causal and non-causal events during the looking time experiment. If only the two active training conditions were found to facilitate causal 
perception, it would indicate that contingent visual, proprioceptive, and haptic perceptual experience is not sufficient for the emergence of causal perception. Moreover, this result combined with pattern of response hypothesized to occur in the no training (control) condition would suggest that causal perception is an ability that originates from direct self-produced action experiences within the environment.

Alternatively, in the case that perceptual aspects (haptic, proprioceptive, visual) of active experience are sufficient for learning to occur, and active experience is not necessary, it was hypothesized that perceptual experience in the passive condition may facilitate causal perception. This possibility is bolstered by research on the role of attention allocation during reaching tasks in infancy. Boudreau and Bushnell (2000) found that when infants attempted to achieve a goal that involved a demanding motor action, attentional resources shifted from the goal to the action itself. Given this finding, passive physical experience in the Passive/Interaction condition of the current study could potentially provide an ideal tradeoff between reaching demands and learning success, as passive physical experience could free up attentional resources that could be allocated toward learning about causality. If the combination of haptic and visual experience during sticky mittens training is sufficient for learning about causality to occur, it was hypothesized that infants in the Passive/Interaction condition would demonstrate the ability to distinguish between causal and non-causal launching events following training.

Regarding the second goal of the current study, which was to assess the impact of active experience on infants' causal learning in a more naturalistic situation, it was hypothesized that a more real-world, socially-interactive form of SM training would 
serve to promote and enhance any learning that would occur in the Active/Interaction or Passive/Interaction conditions. Specifically, it was hypothesized that infants in the Active/Interaction condition would replicate the effects found in the Active/No Interaction condition, and that the addition of parental interaction would potentially serve to produce a more substantial facilitative effect on infants' causal perception. 


\section{CHAPTER II}

\section{EXPERIMENT}

\section{Methods}

\section{Participants}

The sample consisted of sixty 4-month-old infants (30 girls and 30 boys, $M_{\text {age }}=$ 4.21, $S D=0.47$, Range $=3.45-5.29)$. All participants were healthy, full-term (i.e., gestational age of $>36$ weeks and birth weight $>5 \mathrm{lbs}$ ) infants with normal vision and hearing. The racial/ethnic background of the sample was $84 \%$ Caucasian, $10 \%$ African American, 5\% Hispanic, and 2\% Asian. Participants were recruited from birth records obtained from the Kentucky Cabinet for Health and Family Services (KYCHFS), flyers, Facebook postings targeted to new parents, university listserv, and via word of mouth. Families with infants in the desired age range were contacted via mail, e-mail, Facebook, and/or phone call and invited to participate. Families who volunteered received a small gift (t-shirt, bib, etc.) to thank them for their participation. An additional 44 infants participated in the current study, but their data had to be omitted from the final sample (see Data Reduction in Results section).

\section{Procedure}

After parents provided consent to participate and filled out a demographic questionnaire, infants then participated in SM training and a causal perception habituation task. Additionally, parents filled out a caregiver perception rating questionnaire immediately following the SM training session and completed the Early Motor Questionnaire (EMQ) measure, typically after all other experimental procedures had been completed. 


\section{Sticky Mittens Training}

Materials. A pair of custom-made red "sticky mittens" with red Velcro (loop) sewn to the palms (fashioned to resemble the "sticky mittens" used by Needham, Barrett \& Peterman, 2002; Rakison \& Krogh, 2012) were worn over infants' hands during all SM training sessions. A custom-made set of four yellow "sticky toys" were made from table tennis balls (40mm in diameter). Each ball was covered in lens-shaped strips of yellow Velcro (hook) that were affixed to the balls in a beach-ball pattern using non-toxic thermoplastic hot-melt adhesive (hot glue). The sticky mittens and toys were presented on a white wooden tray measuring $34.61 \mathrm{~cm} \mathrm{x} 34.61 \mathrm{~cm}$ (see Figure 9). The sticky toys rested on half-inch flat washers that were affixed to the tray approximately half an inch apart in a square pattern centered $6.35 \mathrm{~cm}$ from one edge of the tray.

Procedure. Each infant was randomly assigned to one of three SM training conditions or a no training condition (see below for details). Infants assigned to the no training condition completed the habituation task first, and then completed the SM training session. Infants assigned to any of the three experimental conditions completed the SM training session prior to completing the habituation task. 


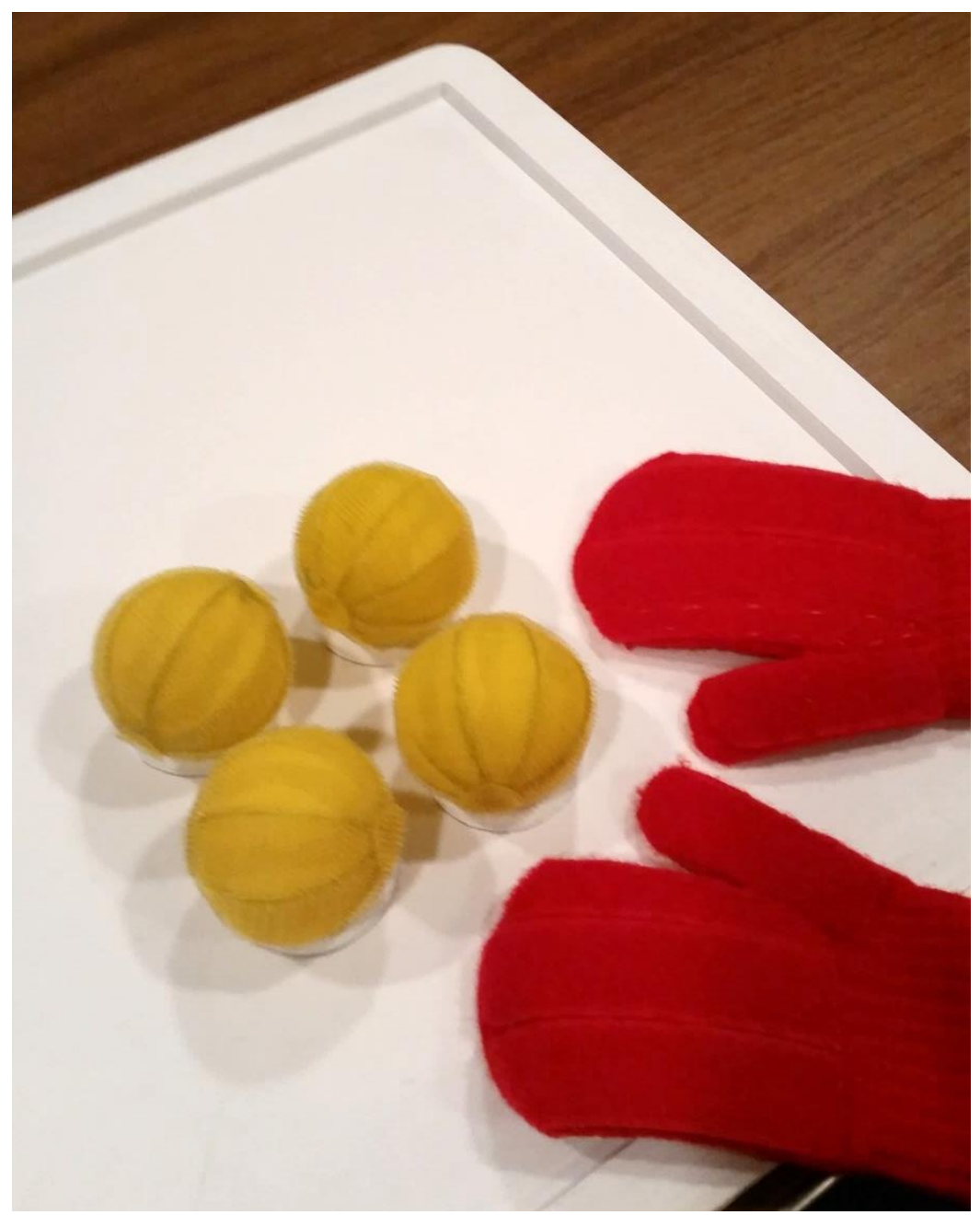

Figure 9. SM training materials used in the present study.

During the SM training phase of the experiment, infants were seated in a parent's lap at a small table across from an experimenter in a well-lit room. Parents were asked to support their infants at the waist and to sit as close to the table as possible. In the event that the parent's lap was not high enough for the child to sit at a height that allowed the infants' arms to reach the toys over the front of the table, a small pillow was placed underneath the infant. Once the infant was seated close enough to the table and at an appropriate height, the experimenter placed the training materials on the table in front of the infant, and the parent was asked to fit the mittens over the infants' hands. Parents then 
received verbal instructions read from a script by an experimenter that differed based on training condition (see Appendices A-C). Instructions were adapted from a script used by Libertus and Needham (2011, 2014). Each SM training session lasted approximately 10 minutes. If an infant became fussy during the training session, the experimenter asked the parent if they wanted to give their infant a short break in order to calm them and continue the session. If the parent deemed the infant too fussy to continue then the play session ended. All infants had to complete at least 3 minutes of training to be included in the final dataset. Video and audio data from the SM training sessions were recorded using a webcam and microphone attached to a MacBook Pro laptop that was placed approximately three feet away from the table at an angle of $45^{\circ}$ to the front and left of the infant-parent dyad. A second, backup video recording of the SM training session was recorded using a Canon VC-C50i camera that was located approximately two-and-a-half feet away from the table at an angle of $90^{\circ}$ to the left of the infant-parent dyad.

Types of Training. In all of the training conditions parents were instructed to draw their infant's attention to the training stimuli and demonstrate once how the toys stick to the mittens by guiding the child's hand to the toy and making it stick. Once the toy was attached to the mitten, parents were asked to shake the child's hand to draw attention to it again. After 10 seconds the toy was removed from the mitten and replaced on the tray. After the demonstration procedure was completed, the instructions parents received differed based on condition. The instructional and procedural differences between each of the training conditions are briefly described below.

In the Active/Interaction (AI) group, parents were instructed to allow their baby to reach for the toys independently while encouraging their reaches by pointing at the 
toys and saying, "Can you get it?" Parents were also instructed to praise their child's successful reaches. Each time the child picked up a toy with their mitten they were allowed to inspect the toy on the mitten for approximately 10 seconds before it was removed from the mitten and replaced on the tray. This procedure was repeated for the duration of the session. These same instructions were also given to parents whose child was assigned to the CTRL group (see Appendix A).

In the Active/No Interaction ( $\mathbf{A N}$ ) group, the training task was identical to the AP training described above, except that parents were specifically instructed that they were not allowed to talk at all during the training session (i.e., parents were instructed not to encourage or verbally reinforce their child's reaching behaviors; see Appendix B).

In the Passive/Interaction (PI) group, parents were instructed to repeat the initial demonstration process (guiding the child's hand to the object, waving the object in front of them, etc.) for the duration of the training session. Parents were also instructed to provide encouragement as if the child were acting independently (e.g. by saying "Can you get it?"), and to praise the child when the parent helped the child to pick up one of the toys (see Appendix C).

\section{Causal Perception Task}

Infants' perception of causality was measured using a habituation task similar to the Gap and Delay conditions previously used by Cohen \& Amsel (1998). In this task, infants watched one of two non-causal events (gap or delay) during the habituation phase, and then saw both of the non-causal events and a causal event during the test phase. Habituation condition (gap, delay) and test event order was randomly assigned and counter-balanced. 
Stimuli. The stimuli for the causal perception task were modeled after the stimuli used by two previous studies of infants' causal perception (Cohen \& Amsel, 1998; Rakison \& Krogh, 2012), and consisted of animations of three different Michottian events that were rendered in Microsoft Powerpoint and then converted to Quicktime movie (.mov) files. The animations depicted the sequential movement of a red and a yellow circle across the field of view. In each of the events, a yellow circle was first shown at rest in the middle of the screen and then a red circle entered the scene from the left and advanced toward the yellow circle. Then, the red circle remained in the center of the screen as the yellow circle moved toward the right edge of the screen and eventually disappeared. No sounds were played during any of the events. The duration of the events ranged from 8 to 9 seconds, depending on the type of event. The circles travelled across a 50 -inch $(127 \mathrm{~cm})$ television screen at a rate of approximately $14.3 \mathrm{~cm} / \mathrm{s}$. Each circle measured $20 \mathrm{~cm}$ in diameter and subtended approximately $9^{\circ}$ of visual angle on the screen, with the total movement from left to right across the screen subtending approximately $51^{\circ}$ of visual angle. At the end of each event, a blue "curtain" descended over a period of 2 seconds to cover the event space, and then ascended over a period of 2 seconds to reveal the yellow circle in the center of the screen at the start of the next repetition of the event.

As depicted in Figure 10, the causal perception stimulus set consisted of three types of Michottian launching events (one causal and two non-causal). In all three events, the red circle advanced from just outside the left edge of the screen toward the yellow circle resting in the middle of the screen. In the direct launching (causal) event, the red circle ended its movement when it collided with the yellow circle causing the yellow 
circle to move off to the right edge of the screen. The delay (non-causal) launching event was also identical to the direct launching event except that when the red ball made contact with the yellow ball, there was a $1 \mathrm{~s}$ delay before the yellow ball began to move. The spatial gap (non-causal) event was identical to the direct launching event except that the yellow circle began its movement toward the right edge of the screen even though red circle stopped before reaching the yellow circle (creating a spatial gap of approximately $10.3 \mathrm{~cm})$.
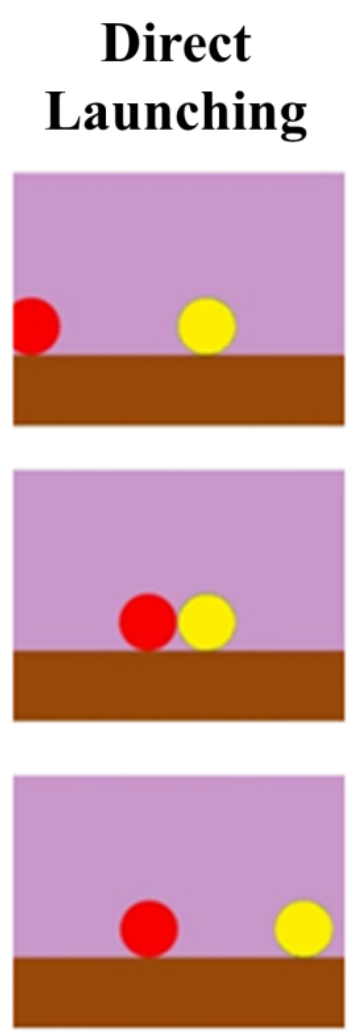

\section{Delayed Launching}
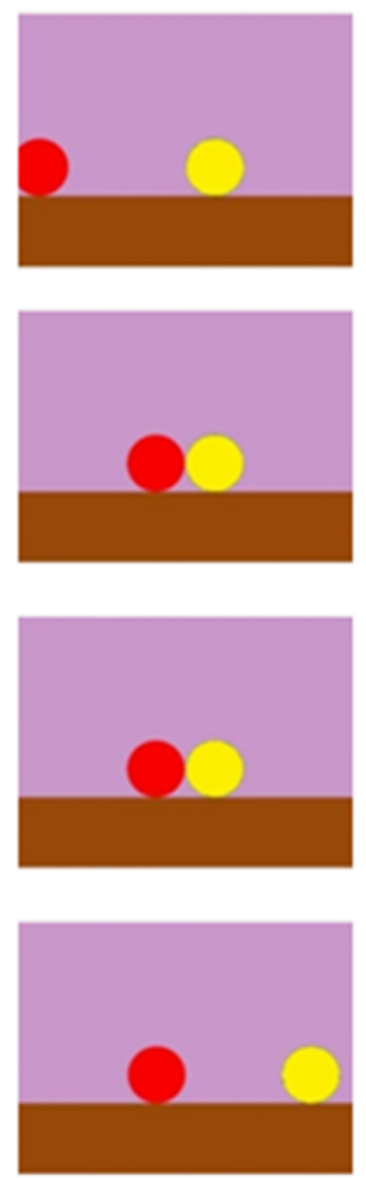
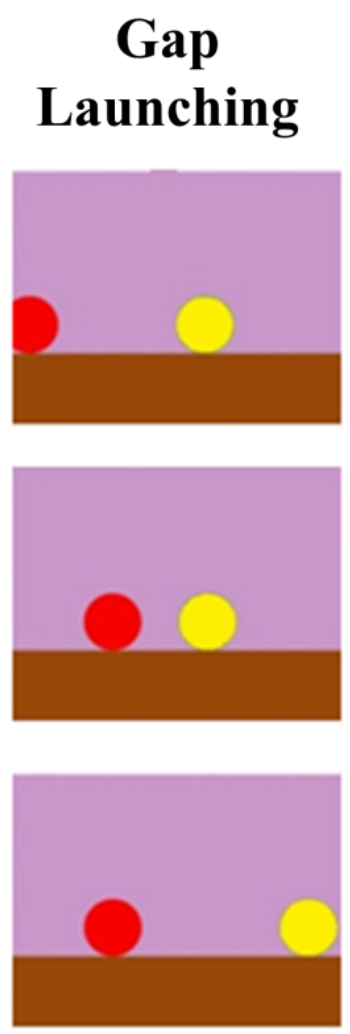

Figure 10. Illustration of animations that were used in the causal perception habituation task. 
Procedure. During the habituation task, infants were seated in a parent's lap approximately $120 \mathrm{~cm}$ away from a 50-inch Panasonic plasma television that was used to display stimuli. The experiment room was dimly lit and soundproofed to prevent distractions. Parents were instructed to avoid pointing, talking, or interacting with their infant during the procedure in order to minimize parental influence on infants' looking behaviors. An experimenter was seated in an adjacent room and observed infants throughout the experiment on a 15-inch JVC closed-circuit monitor that displayed a live video feed from a Canon VC-C50i camera that was concealed below the stimulus display. Presentation of stimuli was controlled using Habit X 1.0 software (Cohen, Atkinson, \& Chaput, 2004) running on a Macintosh Power Mac G5 computer. At the beginning of the task an experimenter displayed an attention-getting video, which consisted of a neongreen colored circle that pulsated in the center of a black background while a "dinging" noise played. When the infant fixated on the attention-getting stimulus, the experimenter pressed the "enter" key on the computer's keyboard to initiate the presentation of the stimuli. The attention-getting stimulus was displayed briefly in between each trial of the experiment to reorient infants' attention to the center of the display. Videos of each experiment session were recorded to a DVD so that they could be recoded offline later for reliability by naïve, independent experimenters.

The habituation task was infant-controlled, meaning that the length of stimulus presentation on each trial depended on how long infants looked at the display. Stimulus presentation advanced to the next trial when an infant looked away from the screen for more than 1 second, or after a maximum duration of 30 seconds of looking had 
accumulated. Infants were randomly assigned to be habituated to one the two non-causal Michottian events (either Gap or Delay), during the habituation phase. Infants were deemed to have met the habituation criterion when their average looking time for any set of three consecutive trials was less than or equal to $50 \%$ of their average looking time over the first three trials. The experiment automatically advanced to the test phase when this habituation criterion was reached, or after 20 habituation trials had been presented. During the test phase, infants viewed three different test trials: a familiar event (identical to the habituation event), a novel non-causal event (either Gap or Delay depending on the habituation stimulus), and a novel causal event (Causal). The order of the presentation of these test trials was counterbalanced across infants to control for any potential order effects. The reliability of the looking time data was checked by a second trained experimenter for a random sample of $25 \%$ of the infants included in the final dataset. The correlation between the looking times recorded by the live experimenter and the offline experimenter was high, $r=.99$.

\section{Early Motor Questionnaire}

Motor development was measured using the Early Motor Questionnaire (EMQ;

Libertus \& Landa, 2013). The EMQ measures infants' developmental level across a variety of motor abilities (e.g. reaching, sitting, crawling, etc.) and contexts (e.g. sitting at a table, playing on the floor, etc.). The measure consists of 128 items scored on a 5-point Likert-type scale. The items are scored on a scale ranging from -2 (certain the infant does not show the behavior) to +2 (certain the infant does show the behavior and can remember a specific instance). The EMQ is divided into 3 subscales: Gross Motor, Fine Motor, and Perception-Action domains. The EMQ has been shown to be highly 
correlated with age across all three sub-scales (Libertus \& Landa, 2013) and also shows high concurrent and predictive validity with the corresponding sections of the Mullen Scales of Early Learning (MSEL) and the Peabody Developmental Motor Scales (PDMS2).

\section{Caregiver Perception Rating Scale}

Immediately following the SM training session in all conditions parents were asked to complete a modified version of a caregiver perception debriefing questionnaire that is included in the Communication and Symbolic Behavior Scales (CSBS; Wetherby \& Prizant, 2002). Parents were asked to indicate whether their child's performance during the SM training session was less than typical, typical, or greater than typical for the following six items: (1) alertness, (2) emotional reaction, (3) level of interest and attention, (4) comfort level, (5) level of activity, and (6) enjoyment (see Appendix D). This questionnaire was included in order to assess whether infants' performance during the in-lab SM training session was representative of their typical at-home behavior.

\section{Results}

\section{Data Reduction}

Only data from infants who successfully completed the SM training task and the causal perception habituation task, and whose parents completed the motor development measure were included in the final sample. Data from twenty-eight infants had to be removed from the final sample for the following specific reasons: (a) parent failure to comply with task instructions ( $n=3, \mathrm{SM}$ training), (b) infant fussiness ( $n=2, \mathrm{SM}$ training; $n=4$, causal perception), (c) parent interference ( $n=1$, causal perception), (d) 
sleepiness and/or inattention ( $n=10$, causal perception), (d) failure to meet habituation criterion ( $n=8$, causal perception). An additional sixteen infants were not included because they demonstrated a familiarity preference (i.e., looked longer at the familiar trial than the two novel trials) during the test phase of the causal perception task. ${ }^{2}$ This exclusion data broken down by condition can be found in Appendix E.

\section{Preliminary Analyses}

Summary statistics of measures used in the preliminary analyses broken down by condition are displayed in Table 1.

Age. In order to demonstrate that infants did not differ in age across training groups, a one-way ANOVA was performed on mean age. Results indicated that age did not differ across conditions, $F(3,56)=0.28, p=.84$.

Motor Development. In order to demonstrate that infants did not differ in terms of their motor development across training groups, a one-way ANOVA was performed on mean EMQ composite score. Results indicated that composite scores on the EMQ did not differ across conditions, $F(3,56)=0.49, p=.69$.

Gender. In order to rule out any potential effects of gender on infants' test trial looking behaviors, a 2 (Gender) X 3 (Test trial) mixed model ANOVA was performed on mean looking time for each test trial. A main effect of gender was not found, $F(1,58)$ $=.041, p=.84$, indicating that infants' overall looking time at test did not differ based on gender. Also, a test trial by gender interaction was not found, $F(2,116)=0.11, p=.90$, indicating that infants' looking times during the test trials did not differ based on gender.

\footnotetext{
${ }^{2}$ The inclusion of infants who show a familiarity preference serves to increase variance, lowers power, and can generally lead to misleading results (Cohen, 2004).
} 
These results suggest that gender was not an important factor and was not included in subsequent analyses.

Habituation Stimulus. Infants were randomly assigned to view one of two possible non-causal events during the habituation phase of the current study. In order to rule out potential effects of habituation stimulus on infants' test trial looking behaviors, a 2 (Hab stimulus) X 3 (Test trial) mixed model ANOVA was performed on mean looking time during the test trials. Neither a main effect of habituation stimulus, $F(1,58)=0.25$, $p=.61$, nor a test trial by habituation stimulus interaction was not found, $F(2,116)=$ $0.32, p=.72$, indicating that infants' response patterns toward the test trials did not differ based on habituation stimulus. These results suggest that habituation stimulus was not an important factor. Thus, test trial data are collapsed across habituation stimulus in all subsequent analyses.

Number of Trials to Reach Habituation Criterion. Rakison and Krogh (2012) found that infants in the active SM training group in their study required fewer trials to habituate than those in their control group. In order to test whether there were differences in the number of trials infants needed to habituate across the four training conditions in the present study, a one-way ANOVA and planned comparisons were performed. No differences were found between training conditions in the number of trials to reach the habituation criterion, $F(3,56)=1.23, p=.31, \eta^{2}=.06$. Moreover, planned comparisons revealed no significant differences in the number of trials to habituate between the control condition and each of the three training conditions (all $p s>.34$ ).

Average Looking Time on First Three Habituation Trials. To test whether there were differences in infants' initial level of interest in the habituation launching event 
based on SM training condition, a one-way ANOVA was performed on infants' mean looking time to the first three habituation trials. No differences were found between training conditions, $F(3,56)=1.48, p=.23, \eta^{2}=.07$. 
Table 1

Summary Statistics for Variables Used in the Preliminary and Exploratory Analyses

\begin{tabular}{|c|c|c|c|c|c|}
\hline$\underline{\text { Measure }}$ & $\underline{\text { Total }(n=60)}$ & $\underline{\operatorname{CTRL}(n=16)}$ & $\underline{\mathrm{PI}(n=16)}$ & $\underline{\mathrm{AN}(n=14)}$ & $\underline{\mathrm{AI}(n=14)}$ \\
\hline Age (in months) & $\begin{array}{l}M=4.21 \\
S D=0.48\end{array}$ & $\begin{array}{l}M=4.14 \\
S D=0.41\end{array}$ & $\begin{array}{l}M=4.18 \\
S D=0.58\end{array}$ & $\begin{array}{l}M=4.25 \\
S D=0.47\end{array}$ & $\begin{array}{l}M=4.29 \\
S D=0.46\end{array}$ \\
\hline $\begin{array}{l}\text { Early Motor Questionnaire (EMQ) } \\
\text { Composite Score }\end{array}$ & $\begin{array}{l}M=-127.3 \\
S D=29.82\end{array}$ & $\begin{array}{c}M=-131.38 \\
S D=18.37\end{array}$ & $\begin{array}{c}M=-121.94 \\
S D=47.23\end{array}$ & $\begin{array}{c}M=-123.43 \\
S D=22.14\end{array}$ & $\begin{array}{c}M=-132.64 \\
S D=21.89\end{array}$ \\
\hline Gender (frequency) & $\begin{array}{c}\text { Male }=30 \\
\text { Female }=30\end{array}$ & $\begin{array}{c}\text { Male }=7 \\
\text { Female }=9\end{array}$ & $\begin{array}{c}\text { Male }=9 \\
\text { Female }=7\end{array}$ & $\begin{array}{c}\text { Male }=8 \\
\text { Female }=6\end{array}$ & $\begin{array}{c}\text { Male }=6 \\
\text { Female }=8\end{array}$ \\
\hline Habituation Stimulus (frequency) & $\begin{array}{c}\text { Gap }=30 \\
\text { Delay }=30\end{array}$ & $\begin{array}{c}\text { Gap }=9 \\
\text { Delay }=7\end{array}$ & $\begin{array}{c}\text { Gap }=7 \\
\text { Delay }=9\end{array}$ & $\begin{array}{c}\text { Gap }=6 \\
\text { Delay }=8\end{array}$ & $\begin{array}{c}\text { Gap }=8 \\
\text { Delay }=6\end{array}$ \\
\hline $\begin{array}{l}\text { Number of Trials to Reach } \\
\text { Habituation Criterion }\end{array}$ & $\begin{array}{l}M=9.65 \\
S D=4.09\end{array}$ & $\begin{array}{l}M=9.38 \\
S D=4.62\end{array}$ & $\begin{array}{l}M=10.06 \\
S D=3.21\end{array}$ & $\begin{array}{l}M=11.00 \\
S D=4.64\end{array}$ & $\begin{array}{l}M=8.14 \\
S D=3.63\end{array}$ \\
\hline $\begin{array}{l}\text { Average Looking Time on First } \\
\text { Three Habituation Trials (s/trial) }\end{array}$ & $\begin{array}{l}M=18.65 \\
S D=7.52\end{array}$ & $\begin{array}{l}M=16.84 \\
S D=7.96\end{array}$ & $\begin{array}{l}M=21.93 \\
S D=6.58\end{array}$ & $\begin{array}{l}M=17.98 \\
S D=8.29\end{array}$ & $\begin{array}{l}M=17.65 \\
S D=6.78\end{array}$ \\
\hline
\end{tabular}




\section{Main Analyses: Effects of SM Training Conditions on Causal Perception}

Infants' mean looking times during the test trials for each condition are presented

in Figure 11. The critical question in the present study was whether infants' patterns of looking times toward the familiar, causal and non-causal test trials differ across conditions and depending on the training condition are more or less consistent with a "conceptual" response or a "perceptual" response. To recap, it was reasoned that if infants respond on the basis of the conceptual change from habituation to test, after being habituated to a non-causal event, they should dishabituate to the causal test event (which is novel conceptually), but not the novel non-causal test event (which is familiar conceptually). On the other hand, if they responded on the basis of perceptual differences during test, infants would be expected to dishabituate to both the causal and novel noncausal test trials, which are both perceptually novel. In order to test address this question, a series of planned comparisons were conducted to compare infants' looking times toward the familiar, novel non-causal, and causal events in each condition. The method of testing predictions by omitting the omnibus ANOVA in favor of planned comparisons has been thoroughly validated (Howell, 1996; Rosenthal, Rosnow \& Rubin, 2000; Wilcox, 1987) and follows the approach used previously by Rakison and Krogh (2012). 


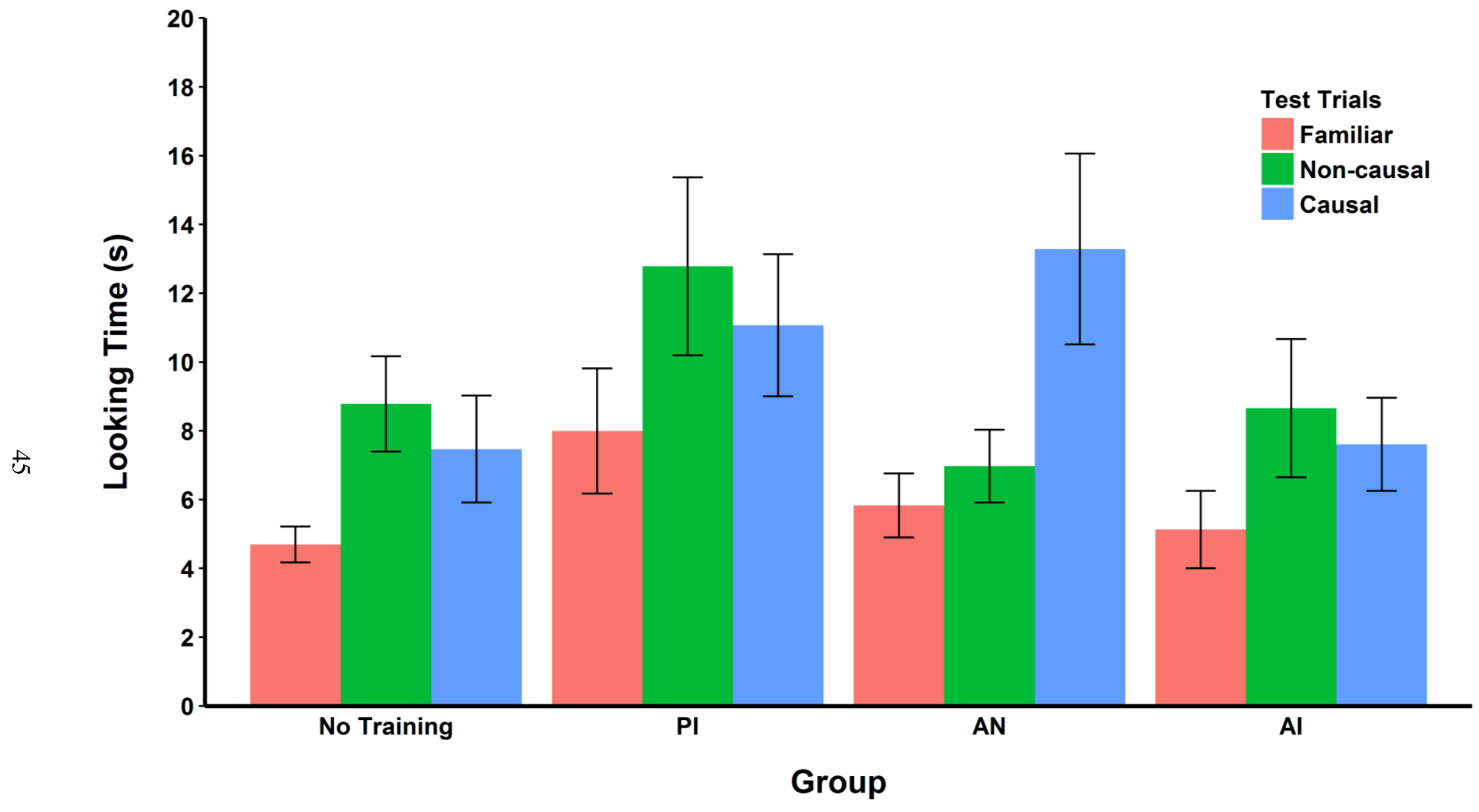

Figure 11. Mean test trial looking times by training condition. Error bars represent standard error. 
Based on previous findings (e.g. Cohen \& Amsel, 1998), it was hypothesized that 41/2-month-old infants in the control condition would demonstrate a pattern of looking at test that was indicative of a perceptual response (i.e., dishabituation to both the novel non-causal test trial and the novel causal test trial). Consistent with this hypothesis, planned comparisons for the control condition revealed that infants' looked significantly longer at the non-causal test trial than the familiar test trial, $t(15)=-2.67, p=.02, d_{z}$ $=.67 .{ }^{3}$ Additionally, they looked significantly longer during the causal test trial than in the familiar trial, $t(15)=-2.23, p=.04, d_{z}=.56$. Together, this pattern of results indicates that, as hypothesized, 41/2-month-old infants in the control condition responded to the perceptual differences between each of the test events.

Passive training (PI) was hypothesized to produce a response pattern at test similar to that found in the control condition. However, unlike previous studies, the passive training condition used in the present study provided infants with contingent haptic, proprioceptive, and visual experiences that could be sufficient to facilitate causal perception. Thus, it was also possible that passive training could have facilitated causal perception, in which case infants should look similarly toward the familiar and noncausal test trials and only dishabituate to the causal test trial. In the PI condition, infants looked significantly longer at the non-causal test trial than the familiar test trial, $t(15)=-$ 2.53, $p=.02, d_{z}=.63$. However, infants' looking time toward the familiar test trial and causal test trial did not differ significantly, $t(15)=-1.32, p=.21, d_{z}=.33$. At first glance, this pattern of results does not fit precisely with either of the hypothesized patterns of

${ }^{3}$ All effect size calculations for planned comparisons were conducted using G*Power 3.1 Software (Faul, Erdfelder, Lang, \& Buchner, 2007; Faul, Erdfelder, Buchner, \& Lang, 2009). 
results. Yet, given that infants dishabituated to the novel non-causal test trial, it is clear that they were not responding to that test event on the basis of causality and instead were likely responding to the novel perceptual cues. The reason a statistically significant difference between the familiar and causal test trials was not found may be due to the relatively higher mean and SD on the familiar test event in that condition. To explore this further, two infants were omitted from this analysis for looking greater than 2SD above the grand mean (cut off: $15.5 \mathrm{~s}$ ) on the familiar test trial $(29.4 \mathrm{~s}$ and $18.5 \mathrm{~s})$. When these outliers were omitted from the data, planned comparisons showed that infants dishabituated to both the novel test trials $(p s<.05)$. Thus, this pattern of results suggests that infants responded on the basis of perceptual changes in the events and that passive SM training does not facilitate the emergence of causal perception in $4 \frac{1}{2} 2$-month-old infants.

The two conditions that provided infants with active training, AN and AI, were hypothesized to facilitate infants' causal perception in the present study. Planned comparisons for the AN condition revealed that there was no difference between infants' looking times toward the familiar test trial and the non-causal test trial, $t(13)=-1.08, p$ $=.30, d_{z}=.29$. Critically, infants' looking times toward the causal test trial were significantly higher than looking times toward the familiar test trial, $t(13)=-2.65, p$ $=.02, d_{z}=.71$. This pattern reflects a pattern similar to that of the $61 / 4$-month-olds tested by Cohen and Amsel (1998) and indicates that active training with no parental interaction facilitates causal perception in 41/2-month-olds. This finding also replicates the findings in the active condition of Rakison and Krogh (2012). 
For the AI condition, which was designed to provide infants with active SM training experience in a more naturalistic context (i.e., with parent interaction), planned comparisons revealed that infants looked significantly longer at the non-causal test trial than the familiar test trial, $t(13)=-2.76, p=.02, d_{z}=.74$. No difference was found in infants' looking times toward the familiar test trial and causal test trial, $t(13)=-1.66, p$ $=.12, d_{z}=.44$. As was done in the PI condition, one outlier was omitted for looking 18.5 s on the familiar test trial. Planned comparisons after the omission of this data point revealed a difference between the familiar and causal test trial that approached statistical significance, $t(12)=-2.04, p=.065$. Surprisingly, the overall pattern of test results for the AI condition is consistent with the conclusion that infants responded on the basis of perceptual cues and suggests that active SM training with parental interaction does not facilitate the emergence of causal perception in 4-1/2 -month-old infants.

\section{Exploratory Analyses: Potential Explanations for the Failure of the AI Condition}

In order to gain a better understanding of why active training combined with parental interaction (AI) failed to facilitate causal perception while active training alone (AN) produced a positive learning outcome, differences between the AI and AN conditions were explored on several important infant characteristics (see Table 1) and parent perceptions (see Table 2) as well as infant object exploration behaviors during the SM task (see Table 3).

Infant Characteristics and Parent Perceptions. No differences were found between the AI and AN groups in terms of age $(p=.81)$, number of trials to habituate ( $p$ $=.15)$, EMQ composite score $(p=.51)$, or total duration of looking at test $(p=.34)$ (see Table 1). Parents' perceptions of their infants' behaviors during the SM training session 
were also examined by comparing scores on each of the six items from the Caregiver Perception Rating Scale (see Table 2). Parent ratings indicated that infants in the AI and AN groups did not differ statistically significantly in terms of their alertness $(p=.38)$, emotional reaction $(p=.88)$, level of interest and attention $(p=.07)$, comfort level $(p$ $=.90)$, level of activity $(p=.67)$, or enjoyment $(p=.39)$. These analyses provide evidence that the difference in learning outcomes observed on the causal perception task between the two active groups is not easily explained by any of the measured infant characteristics or parents' perceptions of their infants' performance during training.

Table 2

Means of Parents' Ratings of Their Infants' Experience During SM Training

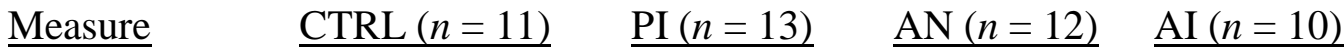

Alertness

Emotional Reaction

Level of Interest and Attention

Level of Comfort

Level of Activity

Enjoyment
1.9

1.7

1.8

1.9

1.9

1.6
1.9

1.9

1.6

1.8

1.9

1.9

Possible scores ranged from 1 (less than typical) to 3 (greater than typical) 
Infant Object Exploration Behaviors during SM Training. To more objectively explore whether infants' object-directed behaviors differed during training, several behavioral variables from the play session were coded for a preliminary sample of eight infants in both the AN and AI conditions (see Table 3). Due to the lower sample size, non-parametric Mann-Whitney U tests were conducted and indicated that infants' behaviors did not differ during the SM training session with regard to the total number of successful reaches $(p=.20)$, the number of successful single-handed reaches $(p=.28)$, the number of successful bimanual (two-handed) reaches $(\mathrm{p}=.57)$, the total duration that objects were attached to the mittens $(\mathrm{p}=.38)$, and the average duration that objects were attached to the mittens per touch $(\mathrm{p}=.72)$. These preliminary analyses suggest that infants in the two active groups produced similar behaviors and presumably had similar opportunities to learn about causality during their respective SM training sessions. Thus far, no evidence has been found that the difference in learning outcomes between the two active training groups can be readily explained by differences in infants' performance during training. 
Table 3

Summary and Comparisons of Measures of Infants' Object-directed Reaching

Behaviors During the SM Training Session Between the AN and AI Groups

$\underline{\text { Measure }} \quad \underline{\mathrm{AN}(n=8)} \quad \underline{\mathrm{AI}(n=8)} \quad \underline{\text { Mann-Whitney U }} \quad \underline{p \text {-value }}$

Number of

successful reaches

$$
\text { Med }=10.0 \quad \text { Med }=17.0
$$

19.0

.20

Successful single-

handed reaches

$$
\text { Med }=10.0 \quad M e d=16.0
$$

21.5

.28

Successful bimanual reaches

$$
\text { Med }=0.0 \quad M e d=2.0
$$

Duration that objects were attached to

$$
M e d=150.5 \quad M e d=180.5
$$

mittens (s)

Average duration objects were attached

Med $=14.9 \quad M e d=12.4$

28.0 .72 to mittens (s/reach) 


\section{Discussion}

The primary goal of this dissertation project was to determine whether the selfproduced nature of infants' object interactions during active SM training is the driving mechanism behind the task's facilitative effects, or whether perceptual aspects (haptic, proprioceptive, visual) of active experience are sufficient for learning to occur. The results of the present study indicate that causal perception can be facilitated through selfproduced actions. Infants who received active SM training with no parent interaction demonstrated a pattern of response during the habituation task that is indicative of causal perception. Importantly, in the absence of self-produced action, the sensory cues to causality that are generated during SM training are not sufficient to facilitate young infants' learning about causality, at least not in the presence of parent interaction.

The findings of the current study, along with those of Rakison and Krogh (2012), strongly implicate the experience of self-produced causal actions as the mechanism by which causal perception arises. The results presented here suggest that the developmental progression previously observed for infants' causal perception between 4 and 6 months of age (e.g., Cohen \& Amsel, 1998) may be the result of the development of the ability to reach for and manipulate objects, which occurs over this same period of development. Perhaps, due their limited motor abilities, 4-month-old infants have simply not yet had the appropriate physical experiences that help catalyze the development of causal perception. From this perspective, one interesting prediction is that young infants who are motorically advanced may naturally become capable of causal perception at an earlier age than their less advanced peers. Future research could empirically test this prediction. 
The current study demonstrates that it is not the case that infants as young as 4 months of age are cognitively incapable of causal perception, but rather they are capable of causal perception if given the "right" type of experience. The second goal of the present study was to assess the impact of active experience on infants' causal learning while using a more naturalistic version of a previously successful in-lab training task (i.e., the task used by Rakison \& Krogh, 2012). It was predicted that both active training conditions would facilitate infants' causal perception. Surprisingly, a discrepancy was found between the learning outcomes of infants in the two active training conditions. Infants who received active training with parental interaction demonstrated a pattern of response during the habituation task that indicated that these infants responded to the perceptual differences between the events, rather than the conceptual difference between causal and non-causal events. Having ruled out differences in motor development and performance during the training task as potential explanations for the difference in learning outcomes between the two active training conditions, it seems likely that parental interaction may have caused an interference effect in the present study. These results suggest that infants are better able to learn about causality from self-produced object explorations experiences that do not involve parental interactions.

In the current study, infants learning about causality may have been hindered by parent interactions for several reasons. For instance, when learning a novel motor skill (e.g., sticky mittens training), attention may be focused on producing the physical movement itself, rather than focused on the movement's effects (Wulf, 2007; Wulf \& Prinz, 2001; Wulf, Shea, \& Lewthwaite, 2010). With further training on the motor skill and better coordination of their actions on the objects during the sticky mittens task, they 
may shift their attention toward the effect of their movements. This shift from an internal focus on movements to an external focus on the movement's effects has been shown to promote learning in adults (Tostika \& Wulf, 2003). Parent interactions during the SM task may serve to distract infants' attention away from the effects of their actions toward dyadic social interactions that are presumably more salient, which may hinder learning (Tomasello \& Farrar, 1986). Allowing infants to sustain their attention without interruption in the AN condition may have been an important feature of the training task that helped facilitate infants' learning. Compared to SM training in which parents do not interact, training that involves parent interaction provided a greater opportunity for infants' attention to be diverted away from the relevant causal object interactions that occur during the task.

Furthermore, the style of interaction parents employ during the SM task may be an important factor that affects infant learning outcomes. Evidence from studies of infant language learning demonstrates that a directive style of interaction (i.e., behaviors or verbalizations that attempt to control infants' behaviors or redirect attention) hinders learning (Marfo, 1992; Mahoney \& Neville-Smith, 1996). The negative effects of directive parent-child interactions are thought to result because parent interactions that cause infants to redeploy their attention may tax infants' cognitive abilities resulting in a disruption of learning. Infants' shifting attention in response to a parental request may negatively affect infants' object manipulations, requiring more effort than simply sustaining attentional focus (Landry \& Chapiesky, 1989; Rocissanoo \& Yatchmink, 1983). Thus, it is possible that parental attempts to redirect attention during SM training may impose additional demands on infants' cognitive resources, resulting in a detrimental 
effect on infant learning outcomes (Tomasello \& Farrar, 1986; Akhtar, Dunham, \& Dunham, 1991). More research is needed to better understand the role of parental interactions in infants learning from SM training and the conditions under which parental interactions may help or hinder the development of causal perception. Future work should examine whether parents exhibit directive interactions during SM training that may explain infants' failure to learn about causality from object exploration experiences that include parent interactions.

One question that falls out of the line of research presented in the current study is what exactly is being learned during the SM training that is being transferred to infants' performance on the causal perception task? Interestingly, the causal relationship demonstrated by the sticky mittens experience (i.e., that the red mitten attaches to the yellow ball to cause it to move contingently) is different from the causal relationship modeled in the habituation events (i.e., the red object bumps into yellow object to cause it to move independent of the red object). It seems then that the general idea of "cause" is being learned from the task rather than the precise type of causal relationship. But how robust is infants" early notion of "cause" following SM training and throughout the first year of life? There is some evidence to suggest that infants' early concept or representation of causality is still highly input driven. For example, in a follow-up experiment, Rakison and Krogh (2012) tested whether infants would generalize their learning about causality from an active SM training task involving blue mittens and yellow toys to a set of habituation events that depicted a red ball colliding with a green ball. They found no evidence of causal perception when the colors of the agent (mitten) and patient (toy) were altered during the habituation experiment. Additionally, Oakes and 
Cohen (1990) found that when the objects depicted in launching events were visually complex, 10-month-olds were able to discriminate between causal and non-causal version of the events, but 6-month-olds failed to show evidence of causal perception. This pattern does not exist when simpler stimuli are used (Oakes, 1994). Together, this evidence suggests that infants' early ability to infer causality from visual events is quite fragile. Although the present study suggests that causal perception originates from early selfproduced actions and can generalize to a novel causal relationship (i.e., a hand in mitten carrying a toy is generalized to a ball launching another ball), the concept of causality certainly continues to undergo a great deal of development over the first year of life, and beyond.

Michotte (1963) and others have contended that causal perception is an innate ability. The present study included a randomized, same-aged control group in which infants received no training prior to the measurement of their ability to perceive the difference between causal and non-causal events. The inclusion of the control condition makes the present study the first to definitively demonstrate that causal perception arises as the result of direct experience actively manipulating objects. When taken together, the results found for the AN condition and the control condition lead to the conclusion that causal perception is an acquired ability. The results presented in the present study imply that causal perception is an ability that requires top-down input derived through active object-manipulation experiences. Thus, Michotte's assertion that causal perception is an automatic, irresistible perceptual phenomenon encapsulated from top-down influence is not supported by the current study. On the contrary, the present study supports several theories of the origin of causal perception that suggest that agentive experiences causally 
manipulating objects constitute the mechanism by which causal perception arises (James, 1890; Maine de Biran, in Michotte, 1963; Piaget, 1954; White, 2009). Moreover, with regard to the origin of causal cognition, Michotte (1963) and others have argued that causal perception is a purely visual phenomenon that is separate from causal inference. However, the results of the present study demonstrate that infants' independent selfproduced causal actions can facilitate causal perception in infancy at an age when causal perception has not yet naturally developed. These results, then, imply that causal perception is a learned ability that requires input from experiences of acting upon objects in a causal manner.

\section{Limitations and Future Directions}

The present study provided no evidence that experiencing causality via contingent haptic, proprioceptive, and visual information facilitates the emergence of causal perception. At this point, however, the possibility that passive experience could still have a facilitative effect cannot be ruled out. An important limitation of the present study is that a condition in which infants were provided passive training in the absence of parent interaction was not included. Because an interference effect was found when infants received active training with parent interaction, it is possible that parent interference could potentially explain the results obtained in the PI condition as well. In order to eliminate the possibility that infants in the PI condition failed to learn about causality because of parent interaction, it is necessary to provide infants with passive training without parent interaction. Thus, the possibility remains open that passive training could facilitate causal perception in 41/2-month-olds. If this passive/no interaction condition were tested, two possibilities arise. The first is that passive training without parent interaction facilitates causal perception. If this is the case, then it is likely that infants 
need to learn about force rather than agency in order to generalize their experience to aid in understanding causal events. However, if it is the case that infants who receive passive training without parent interaction do not demonstrate causal perception, then active experience would be implicated as the source of infants' early ability to perceive causality, although only without parent interactions. In this case, the results would imply that information about agency is important in the development of causal perception in infancy.

The results obtained in the current study suggest that self-produced causal action experience is an important factor that supports young infants' learning about the causal interactions between objects, but the current study falls short of providing evidence that self-produced action alone is the mechanism by which causal perception arises. In the current study, the self-produced action that leads to causal perception was confounded by simultaneous haptic and visual sensory experiences. What is not known, from the current study, is how important the haptic and visual experiences are in the effects of selfproduced action. There is some evidence to suggest that young infants may be able to learn novel cause-and-effect relationships from self-produced actions that do not involve haptic sensory input. In a recent study by Wang et al. (2012), 6- and 8-month-olds' were given the opportunity to cause an event to occur using their eye movements. Using an eye-tracker, researchers presented infants with a red circle on a white background on a computer screen. When infants looked at the red circle for 600 milliseconds an event was triggered in which a "bing" sound was played and a picture of an animal appeared. After the picture was displayed for 1.5 seconds the sequence started over and infants were again allowed to "press" the "button" using their gaze. Results of this study demonstrated 
that although the button was visible for the duration of the task, infants spent more time fixating on the animal pictures, and only looked at the button to produce the image again. Additionally, infants' reaction times decreased significantly over their first three "presses" indicating that they rapidly learned the association between their action and the function of the button. Of course, infants in Wang et al.'s (2012) first experiment may have "pressed" the button simply because it was the only object on the screen after the picture disappeared. To control for this possibility, the authors tested a new group of infants of the same ages, and a group of adults, on a new task in which two buttons were presented on the screen. This time, only one of the buttons triggered the appearance of the animal image, and after it appeared, the image began to slowly fade from the screen. Only 9 out of 25 adults reported that they understood the function of the buttons following the experiment. Infants, and the adults who reported understanding the purpose of the buttons, showed a significant visual preference for the useful button throughout the task. Adults who did not discern the function of the buttons looked equally at both of them. These results suggest that infants may be more open or sensitive to novel forms of agency than adults and also support the idea that action-contingent tasks (e.g., active sticky mittens training) may allow infants to rapidly discover that they are able to perform a novel causal action, which may in turn serve to provide cues to the infant about its own agency and facilitate causal perception. Future studies should seek to test whether active self-produced object manipulation experience in the absence of physical experience can elicit causal perception. This could be accomplished by creating eyetracking training tasks that allow infants to move objects on a screen using their eye movements in a manner analogous to sticky mittens training. 
Future research should also consider how infants' experience with objects affects their predictions about how those objects will behave. For instance, it would be interesting to examine whether experience manipulating differently sized and weighted objects might impose top-down effects on infants performance in a visual habituation task. For example, if young infants who are given experience manipulating weighted objects respond differently to launching events involving those objects compared to infants who did not manipulate them, this would add further support to the idea that haptic and proprioceptive input from self-produced acts generates predictions about causality in launching events.

As highlighted above, an important implication of the current study is that if young infants are provided with an earlier opportunity to exercise volitional control over the physical world, they may reach cognitive milestones, such as understanding physical causality, at an earlier age. From this idea, it follows that infants who are unable to interact with the environment in meaningful ways will not receive the kind of experience that is necessary for the development of robust causal representations, or at least that their representations should develop much more slowly than in typically developing infants. This prediction could be investigated by studying the emergence of causal perception in populations of infants with delayed or impaired motor development, such as infants and toddlers with Cerebral Palsy.

\section{Conclusions}

Based on the present findings and those of Rakison and Krogh (2012), the ability to perceive cause-and-effect relationships in the external world can be facilitated by the ability to act upon objects in a causal manner. The results of Rakison and Krogh's (2012) study, together with the findings of this dissertation project, establish a body of work that 
suggests that causal perception is not necessarily separate from causal inference.

Information learned through self-produced action experiences serves as direct input that facilitates causal perception in infancy, which implies that that causal perception is not merely a perceptual phenomenon. The present findings also suggest that infant learning may not always benefit from parental interactions. Evidence from this study suggests that when infants are learning a new skill, it may be beneficial to allow infants to explore independently, without distraction. 


\section{REFERENCES}

Akhtar, N., Dunham, F., \& Dunham, P. J. (1991). Directive interactions and early vocabulary development: The role of joint attentional focus. Journal of Child Language, 18, 41-49. doi:10.1017/S0305000900013283

Ball, W. A. (1973). The perception of causality in the infant. Paper presented at the Meeting at the Society for Research in Child Development.

Boudreau, J. P., \& Bushnell, E. W. (2000). Spilling thoughts: Configuring attentional resources in infants' goal-directed actions. Infant Behavior and Development, 23, 543-566.

Cohen, L. B. (2004). Uses and misuses of habituation and related preference paradigms. Infant and Child Development, 13, 349-352.

Cohen, L. B., \& Amsel, G. (1998). Precursors to infants' perception of the causality of a simple event. Infant behavior and development, 21, 713-731.

Cohen, L. B., Amsel, G., Redford, M. A., \& Casasola, M. (1998). The development of infant causal perception. In A. Slater (Ed.), Perceptual development: Visual, Auditory, and Speech Perception in Infancy (pp. 167-209). East Sussex, UK: Psychology Press Ltd.

Cohen, L. B., Atkinson, D. J., \& Chaput, H. H. (2004). Habit X: A new program for obtaining and organizing data in infant perception and cognition studies (Version 1.0). Austin: University of Texas.

Danks, D. (2009). The psychology of causal perception and reasoning. In H. Beebee, C. Hitchcock, \& P. Menzies (Eds.), Oxford handbook of causation (pp. 447-470). Oxford: Oxford University Press. 
Desrochers, S. (1999). Infants' processing of causal and noncausal events at 3.5 months of age. The Journal of genetic psychology, 160(3), 294-302.

Faul, F., Erdfelder, E., Lang, A.-G., \& Buchner, A. (2007). G*Power 3: A flexible statistical power analysis program for the social, behavioral, and biomedical sciences. Behavior Research Methods, 39, 175-191.

Faul, F., Erdfelder, E., Buchner, A., \& Lang, A.-G. (2009). Statistical power analyses using $\mathrm{G}^{*}$ Power 3.1: Tests for correlation and regression analyses. Behavior Research Methods, 41, 1149-1160.

Gerson. S. \& Woodward, A. (2013). Learning from their own actions: The unique effect of producing actions on infants' action understanding. Child Development. doi: 10.1111/cdev.12115

Howell, D.C. (1996). Statistical methods for psychology (4th edn.). Belmont, CA: Wadsworth.

Hume, D. (1740/1978). A treatise of human nature. L. A. Selby-Bigge (Ed.). London: Clarendon.

James, W. (1890).The principles of psychology. New York: Macmillan/Harvard University Press.

Kosugi, D., Ishida, H., \& Fujita, K. (2003). 10-month-old infants' inference of invisible agent: Distinction in causality between object motion and human action. Japanese Psychological Research, 45, 15-24. doi:10.1111/1468-5884.00029

Kotovsky, L., \& Baillargeon, R. (1998). The development of calibration-based reasoning about collision events in young infants. Cognition, 67, 311-351. doi:10.1016/S0010-0277(98)00036-5 
Landry, S. H., \& Chapieski, M. L. (1989). Joint attention and infant toy exploration: Effects of Down syndrome and prematurity. Child Development, 60, 103-118. doi: $10.2307 / 1131076$

Leslie, A. M. (1982). The perception of causality in infants. Perception, 11, 173-186.

Leslie, A. M. (1984). Spatiotemporal continuity and the perception of causality in infants. Perception, 13, 287-305.

Leslie, A. M. (1986). Getting development off the ground: Modularity and the infant's perception of causality. In P. van Gest (Ed.), Theory building in development (pp. 405-437). Amsterdam: North Holland.

Leslie, A. M. (1988). The necessity of illusion: Perception and thought in infancy. In L. Weiskrantz (Ed.), Thought without language, (pp. 185-210). Oxford: Clarendon Press/Oxford University Press.

Leslie, A. M. (1995). A theory of agency. In D. Sperber, D. Premack, and A. J. Premack (Eds.), Causal Cognition, (pp. 121-141). Oxford: Clarendon Press.

Leslie, A. M., \& Keeble, S. (1987). Do six-month-old infants perceive causality?. Cognition, 25, 265-288. doi:10.1016/S0010-0277(87)80006-9

Libertus, K., \& Landa, R. J. (2013). The Early Motor Questionnaire (EMQ): A parental report measure of early motor development. Infant Behavior \& Development, 36, 833-842. doi:10.1016/j.infbeh.2013.09.007

Libertus, K., \& Needham, A. (2010). Teach to reach: The effects of active vs. passive reaching experiences on action and perception. Vision Research, 50, 2750-2757. doi:10.1016/j.visres.2010.09.001

Libertus, K., \& Needham, A. (2011). Reaching experience increases face preference in 3- 
month-old infants. Developmental Science. doi: 10.1111/j.1467-

7687.2011.01084.x

Libertus, K., \& Needham, A. (2014). Encouragement is nothing without control: factors influencing the development of reaching and face preference. Journal of Motor Learning and Development, 2, 16-27.

Mahoney, G., \& Neville-Smith, A. (1996). The effects of directive communications on children's interactive engagement: Implications for language interventions. Topics in Early Childhood Special Education, 16, 236-250.

doi:10.1177/027112149601600207

Marfo, K. (1992). Correlates of maternal directiveness with children who are developmentally delayed. American Journal of Orthopsychiatry, 62, 219-233. doi:10.1037/h0079334

Mascalzoni, E., Regolin, L., Vallortigara, G., \& Simion, F. (2013). The cradle of causal reasoning: Newborns' preference for physical causality. Developmental Science, 16, 327-335. doi:10.1111/desc.12018

Michotte, A. (1963). The perception of causality. Oxford, England: Basic Books.

Muentener, P., \& Carey, S. (2006). What is the domain of causal reasoning? Investigating causal perception of motion and non-motion state change events in infancy. Poster presented at the annual meeting of the Vision Sciences Society, Sarasota, Florida.

Muentener, P., \& Carey, S. (2010). Infants' causal representations of state change events. Cognitive Psychology, 61, 63-86. doi:10.1016/j.cogpsych.2010.02.001 
Needham, A., Barrett, T., \& Peterman, K. (2002). A pick me up for infants' exploratory skills: Early simulated experiences reaching for objects using 'sticky' mittens enhances young infants' object exploration skills. Infant Behavior \& Development, 25, 279-295. doi:10.1016/S0163-6383(02)00097-8

Newman, G. E., Keil, F. C., Kuhlmeier, V. A., \& Wynn, K. (2010). Early understandings of the link between agents and order. Proceedings Of The National Academy Of Sciences Of The United States Of America, 107, 17140-17145. doi:10.1073/pnas.0914056107

Oakes, L. M. (1994). Development of infants' use of continutiy cues in their perception of cauality. Developmental Psychology, 30, 869-879.

Oakes, L. M. (2010). Using habituation of looking time to assess mental processes in infancy. Journal of Cognition and Development, 11, 255-268.

Oakes, L. M., \& Cohen, L. B. (1990). Infant perception of a causal event. Cognitive Development, 5(2), 193-207.

Parrinello, R. M., \& Ruff, H. A. (1988). The influence of adult intervention on infants' level of attention. Child Development, 1125-1135.

Piaget, J. (1954). The construction of reality in the child. London: Routledge and Kegan Paul Ltd.

Rakison, D. H., \& Krogh, L. (2012). Does causal action facilitate causal perception in infants younger than 6 months of age?. Developmental Science, 15, 43-53. doi:10.1111/j.1467-7687.2011.01096.x 
Rocissano, L., \& Yatchmink, Y. (1983). Language skill and interactive patterns in prematurely born toddlers. Child Development, 54, 1229-1241. doi: $10.2307 / 1129678$

Rosenthal, R., Rosnow, R.L., \& Rubin, D.B. (2000). Contrasts and effect sizes in behavioral research: A correlational approach.Cambridge: Cambridge University Press.

Schlottmann, A., \& Shanks, D. R. (1992). Evidence for a distinction between judged and perceived causality. The Quarterly Journal of Experimental Psychology A:

Human Experimental Psychology, 44A, 321-342.

doi:10.1080/02724989243000055

Scholl, B. J., \& Tremoulet, P. D. (2000). Perceptual causality and animacy. Trends in Cognitive Sciences, 4, 299-310. doi:10.1016/S1364-6613(00)01506-0

Sloman, S. (2005). Causal models: How people think about the world and its alternatives. New York, NY, US: Oxford University Press.

Sommerville, J. A., Hildebrand, E. \& Crane, C. C. (2008). Experience matters: The impact of doing versus watching on infants' subsequent perception of tool use events. Developmental Psychology, 44, 1249-1256. doi:10.1037/a0012296

Sommerville, J.A., Woodward, A.L., \& Needham, A. (2005). Action experience alters 3month-old infants' perception of others' actions. Cognition, 96, B1-B11. doi:10.1016/j.cognition.2004.07.004

Soska, K. C., Adolph, K. E., \& Johnson, S. P. (2010). Systems in development: motor skill acquisition facilitates three-dimensional object completion. Developmental psychology, 46, 129. 
Spelke, E. S., Phillips, A., \& Woodward, A. L. (1995). Infants' knowledge of object motion and human action. In D. Sperber, D. Premack, A. J. Premack, D. Sperber, D. Premack, A. J. Premack (Eds.), Causal cognition: A multidisciplinary debate (pp. 44-78). New York, NY, US: Clarendon Press/Oxford University Press.

Tenenbaum, J. B., \& Griffiths, T. L. (2003). Theory-based causal inference. Advances in neural information processing systems, 43-50.

Tomasello, M., \& Farrar, M. J. (1986). Joint attention and early language. Child Development, 57, 1454-1463. doi:10.2307/1130423

Tostika, V., \& Wulf, G. (2003). The influence of external and internal foci of attention on transfer to novel situations and skills. Research Quarterly for Exercise and Sport, $74,220-225$.

Vygotsky, L. S. (1987). Thinking and speech. In R. W. Rieber \& A. S. Carton (Eds.), The collected works of L. S. Vygotsky Vol. 1: Problems of general psychology. New York: Plenum Press.

Wang, Q., Bolhuis, J., Rothkopf, C. A., Kolling, T., Knopf, M., \& Triesch, J. (2012). Infants in control: Rapid anticipation of action outcomes in a gaze-contingent paradigm. PloS one, 7, e30884. doi:10.1371/journal.pone.0030884

Wetherby, A. M., \& Prizant, B. M. (2002). Communication and symbolic behavior scales: Developmental profile. Paul H Brookes Publishing.

White, P. A. (2006). The causal asymmetry. Psychological Review, 113, 132-147. doi:10.1037/0033-295X.113.1.132 
White, P. A. (2007). Impressions of force in visual perception of collision events: A test of the causal asymmetry hypothesis. Psychonomic Bulletin \& Review, 14, 647652. doi:10.3758/BF03196815

White, P. A. (2009). Perception of forces exerted by objects in collision events. Psychological Review, 116, 580-601.

White, P. A. (2012). The experience of force: The role of haptic experience of forces in visual perception of object motion and interactions, mental simulation, and motion-related judgments. Psychological Bulletin, 138, 589-615. doi:10.1037/a0025587

Wilcox, R. (1987). New designs in analysis of variance. Annual Review of Psychology, 38, 29-60.

Wulf, G. (2007). Attention and motor skill learning. Human Kinetics: Champaign, IL.

Wulf, G., \& Prinz, W. (2001). Directing attention to movement effects enhances learning: A review. Psychonomic Bulletin \& Review, 8, 648-660.

Wulf, G., Shea, C. and Lewthwaite, R. (2010), Motor skill learning and performance: a review of influential factors. Medical Education, 44, 75-84. doi:10.1111/j.13652923.2009.03421.x 


\section{Appendix A}

Instructions provided to parents during the SM training phase in the AP and CTRL conditions of the present study.

For this part of our study we are going to have you and your child complete a play session. On the table you'll notice a pair of red mittens that have Velcro sewn on the palms. These toys will allow your child to pick up these yellow, Velcro-covered balls. (Demonstrate by picking up a mitten and tapping a ball with the Velcro side)

Before we get started, I'll have you put the Velcro mittens on your baby's hands so that the Velcro is on the palm side of his/her hand. Make sure they are comfortable but won't slip off.

Seat your baby on your lap in front of the table so that your baby can comfortably reach the toys on the table. His/her arms should be above the table. If you think your child is seated too low to reach comfortably we can place a pillow under him/her so that he/she is seated higher.

\section{<EXPERIMENTER: START THE VIDEO RECORDING AND TIMER>}

Now, I'll have you draw attention to the toys in front of your baby by saying: "We are going to play with these now!"

Please demonstrate ONCE how the toy sticks to the mittens by guiding your child's hand to the toy and making it stick. Now, please SHAKE YOUR CHILD'S HAND TO DRAW ATTENTION TO THE ATTACHED TOY. After about 10 seconds, remove the toy from the mitten and place it on the table.

From this point forward, we will allow your baby to reach for the toys independently. If you would like, feel free to draw attention to the toys by pointing to them or by briefly shaking or banging them. Please encourage your child to reach for the toys by asking "CAN YOU GET IT?"

If the toy sticks to the mittens, we ask that you PRAISE YOUR CHILD'S SUCCESS and then remove the toy from the mittens after about 10 seconds.

\section{BE SURE TO REMOVE THE TOY FROM YOUR CHILD'S MITTEN BEFORE THEY} BRING IT UP TO THEIR FACE BECAUSE THE VELCRO MAY BE

UNCOMFORTABLE. After you place the toys back on the table please encourage your child to try again (for example, say: "CAN YOU GET IT AGAIN?").

We will repeat this process until a total of 10 minutes of playtime has passed. 


\section{Appendix B}

Instructions provided to parents during the SM training phase in the PI condition.

For this part of our study we are going to have you and your child complete a play session. On the table you'll notice a pair of red mittens that have Velcro sewn on the palms. These toys will allow your child to pick up these yellow, Velcro-covered balls. (Demonstrate by picking up a mitten and tapping a ball with the Velcro side)

Before we get started, I'll have you put the Velcro mittens on your baby's hands so that the Velcro is on the palm side of his/her hand. Make sure they are comfortable but won't slip off.

Seat your baby on your lap in front of the table so that your baby can comfortably reach the toys on the table. His/her arms should be above the table. If you think your child is seated too low to reach comfortably we can place a pillow under him/her so that he/she is seated higher.

<EXPERIMENTER: START THE VIDEO RECORDING AND TIMER>

\section{THE ONLY RULE FOR THIS TASK IS THAT YOU WILL BE HELPING YOUR BABY BY CONTROLLING YOUR BABY'S ARMS AND GUIDING HIS/HER HANDS TO THE OBJECTS FOR HIM/HER.}

Now, I'll have you draw attention to the toys in front of your baby by saying: "We are going to play with these now!"

Please demonstrate ONCE how the toy sticks to the mittens by guiding your child's hand to the toy and making it stick. Now, please SHAKE YOUR CHILD'S HAND TO DRAW ATTENTION TO THE ATTACHED TOY. After about 10 seconds, remove the toy from the mitten and place it on the table.

From this point forward, YOU WILL CONTINUE TO DIRECT YOUR CHILD'S ARMS AND HANDS TO THE TOYS IN THE SAME MANNER. If you would like, feel free to draw attention to the toys by briefly shaking or banging them. Be sure to encourage your child as you help them reach for the toys by asking "CAN YOU GET IT?"

If the toy sticks to the mittens, we ask that you PRAISE YOUR CHILD'S SUCCESS and then remove the toy from the mittens after about 10 seconds.

PLEASE DO NOT TOUCH THE ATTACHED TOYS TO YOUR CHILD'S FACE, BECAUSE THE VELCRO MAY BE UNCOMFORTABLE. After you place the toys back on the table encourage your child to try again (for example, say: "CAN YOU GET IT AGAIN?").

We will repeat this process until a total of 10 minutes of playtime has passed. 


\section{Appendix C}

Instructions provided to parents during the SM training phase in the AN condition.

For this part of our study we are going to have you and your child complete a play session. On the table you'll notice a pair of red mittens that have Velcro sewn on the palms. These toys will allow your child to pick up these yellow, Velcro-covered balls. (Demonstrate by picking up a mitten and tapping a ball with the Velcro side)

Before we get started, I'll have you put the Velcro mittens on your baby's hands so that the Velcro is on the palm side of his/her hand. Make sure they are comfortable but won't slip off.

Seat your baby on your lap in front of the table so that your baby can comfortably reach the toys on the table. His/her arms should be above the table. If you think your child is seated too low to reach comfortably we can place a pillow under him/her so that he/she is seated higher.

<EXPERIMENTER: START THE VIDEO RECORDING AND TIMER>

\section{THE ONLY RULE FOR THIS TASK IS THAT YOU ARE NOT ALLOWED TO TALK DURING THE PLAY SESSION.}

Please demonstrate ONCE how the toy sticks to the mittens by guiding your child's hand to the toy and making it stick. Now, please SHAKE YOUR CHILD'S HAND TO DRAW ATTENTION TO THE ATTACHED TOY. After about 10 seconds, remove the toy from the mitten and place it on the table.

From this point forward, we will allow your baby to reach for the toys independently. If you would like, feel free to draw attention to the toys by briefly shaking or banging them. But, remember, PLEASE DON'T TALK.

\section{BE SURE TO REMOVE THE TOY FROM YOUR CHILD'S MITTEN BEFORE THEY BRING IT UP TO THEIR FACE BECAUSE THE VELCRO MAY BE UNCOMFORTABLE.}

We will repeat this process until a total of 10 minutes of playtime has passed. 


\section{Appendix D}

Caregiver perception rating scale that parents completed following SM training.

Please compare your child's behavior during the Velcro-mitten play session we have just completed to your observations of your child in similar situations. Circle the response that comes closest to your observations.

1

1. Alertness Less than usual/sleepy typical

2. Emotional reaction

3. Level of interest less than usual and attention

4. Comfort level

more cautious/ wary than usual

5. Level of activity

less active than usual

more negative

than usual

typical

typical

typical

typical

typical

than usual

\section{3}

very alert

greater than usual

more positive than usual

greater interest/

greater attention

more comfortable/ relaxed than usual

more active than usual

more enjoyment than usual

\section{Observations/comments:}




\section{Appendix E}

Reasons that Infants were Excluded from the Final Dataset by Condition

$\underline{\text { Reason for Exclusion }} \quad \underline{\operatorname{Total}(n=44)} \quad \underline{\operatorname{CTRL}(n=10)} \quad \underline{\operatorname{PI}(n=14)} \quad \underline{\mathrm{AN}(n=8)} \quad \underline{\mathrm{AI}(n=12)}$

Parent failed to comply with SM task instructions

Infant fussiness

Parent interfered during habituation

Infant inattention or sleepiness

Failure to meet habituation criterion

Preference for familiar test trial
3

6

1

10

8

16
0

1

0

0

5

4
2

2

0

4

2

4
0

2 


\section{CURRICULUM VITAE}

\section{Nicholas A. Holt}

Department of Psychological and Brain Sciences

317 Life Sciences

University of Louisville

Louisville, KY 40292
Phone: (502) 338-3889

Lab Phone: (502) 852-6852

Email: nicholas.holt@louisville.edu

\section{Professional Positions}

Head Instructor, Institute for Advanced Analytics, Bellarmine University, 2017

Associate Research Scientist, Pacific Institute for Research and Evaluation, 2016

\section{Education}

Ph.D., Experimental Psychology, University of Louisville, Louisville, KY, 2016

M.S., Experimental Psychology, University of Louisville, Louisville, KY, 2013

B.S., Psychology, Morehead State University, Morehead, KY, 2011

\section{Research Interests}

Embodied cognitive development, social cognitive development, motor development, motor learning, causal perception, object perception, face perception, consequences of motor disabilities for cognitive and perceptual development

\section{Honors \& Awards}

Runner-up, University of Louisville Three Minute Thesis (3MT) Competition (2016)

Graduate Entrepreneurship Academy (2016)

Graduate Grant Writing Academy (2015)

Graduate Teaching Assistant (GTA) Academy (2013-2014)

Conference Travel Award, University of Louisville GSC, (\$350 per year; 2012-2014)

$2^{\text {nd }}$ Place Award, Oral Presentation in Psychology, Kentucky Academy of Science (2010)

\section{Funding}

\section{$\underline{\text { Awarded }}$}

- University of Louisville College of Arts \& Sciences Graduate Student Grant for Research and Creative Activities. Mechanisms Responsible for the Emergence of Causal Perception in Infancy. 2015-2016. Amount: \$500.00. 
- University of Louisville GSU Research Grant. Mechanisms Responsible for the Emergence of Causal Perception in Infancy. 2015. Amount: \$100.00.

- University of Louisville Graduate Student Council Research Fund Grant. Mechanisms Responsible for the Emergence of Causal Perception in Infancy. 20142015. Amount: $\$ 300.00$.

\section{Not Awarded}

- NSF Graduate Research Fellowship Program (GRFP). Using eye movements to facilitate causal perception in infancy. Application Date: 11/16/12

\section{Publications}

Cashon, C. H., \& Holt, N. A. (2015). Developmental Origins of the Face Inversion Effect. In Benson, J. B. (Ed.). Advances in Child Development and Behavior. 48, 117-150. San Diego, CA: Elsevier. doi: 10.1016/bs.acdb.2014.11.008

DeNicola, C. A., Holt, N. A., Lambert, A. J., \& Cashon, C. H. (2013). Attention-orienting and attention-holding effects of faces on 4- to 8-Month-Old Infants. International Journal of Behavioral Development, 37, 143-147. doi: 10.1177/0165025412474751

\section{$\underline{\text { Works in Progress }}$}

Ha, O., Cashon, C. H., Holt, N. A., \& Mervis, C. B. (in prep). Rapid Word-Object Association is Related to Expressive Vocabulary Size in Infants and Toddlers with and without Williams Syndrome.

Cashon, C. H., Holt, N. A., Dixon, K. C., \& Woodruff-Borden, J. (in prep). Maternal Negative Affect is related to 5-month-old Infants' Discrimination of Facial Expressions in a Non-clinical Sample.

\section{Presentations}

\section{Peer-reviewed Conference Presentations}

Holt, N. A., Pal, P., Olesen, N. M., Dixon, K. C., \& Cashon, C. H. (submitted). Parent Interaction Disrupts 4-month-old Infants' Learning about Causality during Sticky Mittens Training. Talk submitted to the biennial meeting of the Society for Research in Child Development, Austin, TX.

Holt, N. A., Cashon, C. H. (2016, May). Are differences in the effects of sticky mittens experience on 4-month-olds' perception of causality related to motor development?. Poster presented at the biennial meeting of the International Congress on Infant Studies, New Orleans, LA.

Holt, N. A., Cashon, C. H. (2015, October). Causal perception in 4-month-olds: contributions of self-produced action and parental interaction. Poster presented at the biennial meeting of the Cognitive Development Society, Columbus, OH.

Dixon, K. C., Holt, N. A., Woodruff-Borden, J., \& Cashon, C. H. (2015, October). Same visual input, different cognitive outcome: Differences in 5-month-olds' emotion 
discrimination, but not visual scanning behavior. Poster presented at the biennial meeting of the Cognitive Development Society, Columbus, $\mathrm{OH}$.

Cashon, C. H., Holt, N. A., \& Woodruff-Borden, J. (2015, March). Emotional environment is related to infants' scanning and discrimination of neutral and happy faces. Talk presented at the biennial meeting of the Society for Research in Child Development, Philadelphia, PA.

Holt, N. A., Cashon, C. H., Woodruff-Borden, J., \& Smith, S. G. (2014, July). Parental symptoms of depression and anxiety are related to 5-month-olds' face scanning and discrimination of facial expressions. Poster presented at the biennial meeting of the International Conference on Infant Studies, Berlin, DE.

Ha, O., Cashon, C. H., Holt, N. A., Helton, L. E., \& Mervis, C. B. (2014, July). Rapid wordobject association is related to expressive vocabulary size in infants and toddlers with and without Williams syndrome. Poster presented at the biennial meeting of the International Conference on Infant Studies, Berlin, DE.

Holt, N. A., Patane, R. R., \& White, W. (2010, November). Two hours of amphetamine exposure is sufficient to produce longer-term withdrawal-related hypophagia. Paper presented at the $96^{\text {th }}$ Annual Meeting of the Kentucky Academy of Science, Bowling Green, KY.

Gibbs, D., Patane, R. R., Addison, A. A., Holt, N. A., Dillow, J., \& White, W. (2010, November). A novel procedure for investigating amphetamine-induced withdrawal-related hypophagia. Paper presented at the $96^{\text {th }}$ Annual Meeting of the Kentucky Academy of Science, Bowling Green, KY.

Patane, R. R., Addison, A. A., Holt, N. A., Dillow, J., Gibbs, D., \& White, W. (2010, November). The role of selective dopamine receptor agonists in amphetamineinduced withdrawal-related hypophagia. Paper presented at the $96^{\text {th }}$ Annual Meeting of the Kentucky Academy of Science, Bowling Green, KY.

Osborne, S., Book, D., Holt, N. A., May. L, \& White, I. M. (2009, November). Repeated exposure to psychostimulants on appetitive behavior. Paper presented at the $95^{\text {th }}$ Annual Meeting of the Kentucky Academy of Science, Highland Heights, KY.

\section{Invited Talks}

Holt, N. A. (2015, November). Relations between infants' emerging perceptual, cognitive, and motor abilities. Talk presented at the Morehead State University Department of Psychology Colloquium Series, Morehead, KY.

Holt, N. A., DeNicola, C. A., Ha, O., Helton, L. E., \& Cashon, C. H. (2013, April). Infants' processing and scanning of faces. Talk presented at the biennial meeting of the Society for Research in Child Development - Face Processing Pre-Conference, Seattle, WA.

\section{Other Presentations}

Holt, N. A., Cashon, C. H. (2016, April). Does motor development predict what infants learn about objects from manual exploration experience?. Poster presented at the University of Louisville Graduate Regional Research Conference, Louisville, KY. 
Holt, N. A. (2016, April). Optimizing experience to promote causal learning in infancy. Talk presented at the University of Louisville Graduate Regional Research Conference - Three Minute Thesis Competition (3MT), Louisville, KY. ${ }^{* *}$ This talk placed runner-up in the competition**

Holt, N. A., Cashon, C. H. (2015, October). Causal perception in 4-month-olds: Contributions of self-produced action and parental interaction. Poster presented at Research!Louisville, Louisville, KY.

Dixon, K. C., Holt, N. A., Woodruff-Borden, J., \& Cashon, C. H. (2015, October). Same visual input, different cognitive outcome: Differences in 5-month-olds' emotion discrimination, but not visual scanning behavior. Poster presented at Research!Louisville, Louisville, KY.

Holt, N. A. (2015, March). The development of the face inversion effect during infancy. Talk presented at the University of Louisville Experimental Psychology Brown-bag Seminar Series, Louisville, KY.

Holt, N. A. (2014, January). Rethinking the origin of causal perception. Talk presented at the University of Louisville Experimental Psychology Seminar Series, Louisville, KY.

Smith, S. G., Holt, N. A., Woodruff-Borden, J., \& Cashon, C. H. (2013, July). 5-month-old infants' face scanning patterns differentiate emotion discrimination ability. Poster presented at the University of Louisville Poster Session of Summer Undergraduate Research, Louisville, KY.

Arrowood, A., Holt, N. A., Williams, S., Woodruff-Borden, J., \& Cashon, C. H. (2012, May). Five-month-old infants' discrimination of emotion in faces. Poster presented at the University of Louisville Undergraduate Research Symposium, Louisville, KY.

Addison, A. A., Maione, G., Holt, N. A., \& White, W. (2011, April). Impact of amphetamine and dopamine agonists on acute- and withdrawal-phase feeding in rats. Paper presented at the Morehead State University Celebration of Student Scholarship, Morehead, KY.

\section{Teaching Experience}

Teaching Assistant and Lab Instructor

PSYC 302 - Experimental Psychology, (UofL, Fall 2011; 2012)

PSYC 610 - Advanced Statistics I (PhD Level), (UofL, Fall 2013; 2014; 2015)

PSYC 611 - Advanced Statistics II (PhD Level), (UofL, Spring 2014; 2015; 2016)

\section{$\underline{\text { Teaching Assistant }}$}

PSYC 201 - Introduction to Psychology, (UofL, Spring 2012; 2013)

PSYC 363 - Life-span Developmental Psychology (UofL, Spring 2013; Summer 2013)

\section{Guest Lecturer}

October 2014, Guest lecturer for University of Louisville, Louisville, KY

Course: PSYC-610, Advanced Statistics I, PhD Level

Topic: Matched-sample T-tests \& Effect Size (Cohen's d) 
March 2014, Guest lecturer for University of Louisville, Louisville, KY Course: PSYC-363, Honors Developmental Psychology, Undergraduate Level Topic: Physical and Cognitive Development in Middle Childhood

February 2014, Guest lecturer for University of Louisville, Louisville, KY Course: PSYC-611, Advanced Statistics II, PhD Level Topic: Linear Contrasts \& Multiple Comparisons

February 2014, Guest lecturer for University of Louisville, Louisville, KY Course: PSYC-363, Honors Developmental Psychology, Undergraduate Level Topic: Cognitive Development in Infancy and Toddlerhood

\section{Service and Leadership}

Judge in Computational Biology and Bioinformatics - DuPont Manual High School Regional Science Fair (March, 2016)

Invited speaker - Graduate Student Dean's Reception, University of Louisville, (2015) Graduate Student Representative for Department of Psychological and Brain Sciences (elected), University of Louisville Graduate Student Council, (2014-2015)

Invited Panelist - New Student Q\&A Session, Graduate Student Orientation, University of Louisville School of Interdisciplinary and Graduate Studies (August, 2014)

Head Judge in Social \& Behavioral Sciences - DuPont Manual High School Regional Science Fair (March, 2013; 2014), Judge (March, 2015)

Executive Board Member: VP of Public Relations - Psi Chi Honors Society, Morehead State University, (2011)

\section{Editorial Responsibilities}

Frontiers in Cognitive Science (guest reviewer for special issue on Embodied Cognition) British Journal of Developmental Psychology (ad-hoc reviewer)

\section{Professional Memberships}

American Association for the Advancement of Science (AAAS)

Society for Research in Child Development (SRCD)

International Society on Infant Studies (ISIS)

Cognitive Development Society (CDS)

Kentucky Academy of Science (KAS)

Society for Nueroscience - Louisville Chapter (SfN) 